\title{
Seedless synthesis and efficient recyclable catalytic activity of Ag@Fe nanocomposites towards methyl orange
}

\author{
Salma Ahmed Alzahrani ${ }^{1} \cdot$ Maqsood Ahmad Malik ${ }^{1} \cdot$ Shaeel Ahmed Al-Thabaiti ${ }^{1} \cdot$ Zaheer Khan $^{1}$
}

Received: 2 August 2017 / Accepted: 21 February 2018 / Published online: 5 March 2018

(c) Springer-Verlag GmbH Germany, part of Springer Nature 2018

\begin{abstract}
This work demonstrates a competitive reduction method of synthesis of nanomaterials. In this method along cetyltrimethylammonium bromide (CTAB), the reduction of $\mathrm{Ag}^{+}$and $\mathrm{Fe}^{3+}$ ions is achieved by ascorbic acid-to-bimetallic $\mathrm{Ag} @ \mathrm{Fe}$ yellowcolored nanomaterials. The shape of UV-visible spectra and wavelengths absorbed of Ag@Fe can be tuned from ca. 290$600 \mathrm{~nm}$ by controlling $[\mathrm{CTAB}]$ and $\left[\mathrm{Ag}^{+}\right]$. The apparent first-order rate constants were calculated within the approximation of $6.1 \times 10^{-3} \mathrm{~s}^{-1}$. The as-prepared Ag @Fe NPs have been found to be very important catalyst in terms of depredate methyl orange in vicinity of sodium borohydride $\left(\mathrm{NaBH}_{4}\right)$, which exhibits excellent efficiency and re-usability in the prototypical reaction. The $\mathrm{cmc}$ of cationic surfactant $\mathrm{CTAB}$ has been determined by conductivity method under different experimental conditions. In the presence of $\mathrm{CTAB}, \mathrm{Ag}^{+}$and $\mathrm{Fe}^{3+}$ ions reduce to $\mathrm{Ag} @ \mathrm{Fe}$ core/shell nanoparticles, comprehend a change in wavelength and intensity of SRP band. The apparent first-order rate constant, activation energy, and turnover frequency for the methyl orange reduction catalyzed by Ag@Fe NPs were found to be $1.6 \times 10^{-3} \mathrm{~s}^{-1}, 58.2 \mathrm{~kJ} \mathrm{~mol}^{-1}$, and $1.1 \times 10^{-3}$ $\mathrm{s}^{-1}$, respectively.
\end{abstract}

Keywords Nanomaterials $\cdot$ Ag@Fe core/shell NPs $\cdot$ Ascorbic acid $\cdot$ CTAB $\cdot$ Methyl orange $\cdot$ Catalytic activity

\section{Introduction}

Synthesis of magnetic iron-oxide nanoparticles by various physical and chemical methods, including thermal decomposition, vacuum sputtering, co-precipitation, hydrothermal, and chemical reduction methods has been the subject of interest of nanochemists from three decades due to their technological and clinical applications such as biocompatibility, non-toxic, high-density magnetic recording media, cell separation, accumulation in target tissue, hyperthermia, surgery in cancer therapy, and good dispersion in an aqueous solution (Sun et al. 2000; Hyeon et al. 2001; Mornet et al. 2004; Tsang et al. 2006; Laurent et al. 2008). It is well known that the iron (as fourth abundant transitional metal

Electronic supplementary material The online version of this article (https://doi.org/10.1007/s13204-018-0699-7) contains supplementary material, which is available to authorized users.

Zaheer Khan

drkhanchem@yahoo.co.in

1 Chemistry Department, Faculty of Science, King Abdulaziz University, P.O. Box 80203, Jeddah 21589, Saudi Arabia on Earth's crust act as backbone for making tools and foundations of modern infrastructure) is reactive to both oxygen and water and can eventually be oxidized into weakly ferromagnetic and anti-ferromagnetic species, respectively, rendering particles less useful to hyperthermia (Eq. 1) (Huber 2005):

$\mathrm{Fe}_{(\mathrm{S})}^{0}+2 \mathrm{H}_{2} \mathrm{O}_{(\mathrm{aq})} \rightarrow \mathrm{Fe}_{(\mathrm{aq})}^{2+}+\mathrm{H}_{2(\mathrm{~g})}+2 \mathrm{OH}_{(\mathrm{aq})}^{-}$.

Synthesis and protection of naked transition metal-oxide nanomaterials have been the subject of various investigators using different techniques such as surface passivation, surfactant and polymer coating, precious metal coating, and/ or coating agents (Lin et al. 2001; Sureshkumar et al. 2010; Scholten and Felius 1990; Park and Cheon 2001; Colvin et al. 1992; Stoeva et al. 2005). Laurent et al. have been reported the importance of surface coating for controlled size of iron-oxide surfaces towards micellization besides having vital importance in biodistribution properties, metabolic, vascular clearance, and pharmacokinetics (Laurent et al. 2008). Wang and Zhang and Zhang et al. reported the synthesis of FeNPs using sodium borohydride as a strong reductant in the absence of capping agents (Wang and Zhang 
1997; Zhang et al. 1998). Recently, Ag and Fe monometallic nanoparticle have been synthesized using sodium dodecyl sulphate (SDS) and CTAB/SDS as stabilizing agents, respectively (Al-thabaiti et al. 2016; Khan et al. (2016). Ponder et al. used water-soluble poly(acrylic acid) as nanoparticle supports to the protection of $\mathrm{Ni} @ \mathrm{Fe}$ bimetallic nanoparticles (Ponder et al. 2001). Lu et al. in his pioneering review have mentioned the need to develop new synthetic methods to control shape and size of metallic nanoparticles or watersoluble metal oxides, which serves as current research interest (Lu et al. 2007).

$\mathrm{Xu}$ and Zhang reported a method to the synthesis of subcolloidal iron and $\mathrm{Fe} / \mathrm{Ag}$ nanoparticles. They used two steps process [(i) formation of $\mathrm{Fe}^{0} ; \mathrm{Fe}^{3+}+\mathrm{NaBH}_{4} \rightarrow \mathrm{Fe}^{0}$ ] and (ii) reductive deposition of $\mathrm{Ag}^{+}$on $\mathrm{Fe}^{0} ; \mathrm{Ag}^{+}+\mathrm{Fe}^{0} \rightarrow$ $\left.\mathrm{Ag}^{0}+\mathrm{Fe}^{2+}\right)(\mathrm{Xu}$ and Zhang 2000). Chen et al. have developed a systematic surface double-exchange preparation method for water-soluble monodisperse $\mathrm{Fe}_{3} \mathrm{O}_{4}$ nanoparticles with 2,3-dimercaptosuccinic acid (Chen et al. 2008). Wei et al. have reported the synthesis of core-shell nanomaterials of $\mathrm{Ag} @ \mathrm{Fe}_{2} \mathrm{O}_{3}$ using seed-growth approach (Wei et al. 2011). Various investigators reported bimetallic, core-shell structure synthesis of $\mathrm{Fe}-\mathrm{Ag}$ nanoparticles via reductive deposition of $\mathrm{Ag}^{+}$ions on nanosurface of FeNPs (Ghauch and Tuqan 2009; Luo et al. 2010, 2012). Carroll et al. reported the one-step, aqueous reductive method of synthesis in the presence of strong reducing agents (sodium borohydride and citrate) for $\mathrm{Fe}-\mathrm{Ag}$ core/shell nanoparticles (Carroll et al. 2010a, b). In general, surface-functionalized FeNPs become superparamagnetic at room temperature and their aggregation was a common phenomenon. The magnetic properties can be modified by the coating materials, such as $\mathrm{Au}, \mathrm{Ag}, \mathrm{Co}$, polymers, surfactants, and proteins (Wu et al. 2015). These materials not only retain their individual semiconducting and magnetic functionalities, but also exhibit some new properties due to the coating components. It has been established that iron shows two extremes of oxidation when contact with metals, i.e., slow oxidation with more active metal $(\mathrm{Zn}, \mathrm{Al}$, and $\mathrm{Mg}$ ) and fast oxidation with less active metal (Cu, Pd, and Ag) (Crow 1988). Ferrando et al. in his pioneering review mentioned that metal individuals with higher redox potential are reduced fist to form core while the other with low reduction potential orient themselves onto as shell during a process of co-reduction of two metal ions (Ferrando et al. 2008). Recently, we reported the seedless method of synthesis based on the competitive coordination chemistry of cysteine with $\mathrm{Cu}^{2+}$ and $\mathrm{Ag}^{+}$for stable water-soluble $\mathrm{Ag} @ \mathrm{Cu}$ bimetallic nanostructured material (Khan and Obaid 2016). In general, 4-nitrophenol has been used as an oxidant for the catalytic efficiency evaluation of the mono- and bimetallic nanomaterials ( $\mathrm{Li}$ et al. 2016; Pradhan et al. 2001; Wang et al. 2016). The main focus of this study was to provide convenient and simpler reducible system than the standard synthetic techniques for preparation of water-soluble Ag@Fe NCPs. Our strategy was based on the reactivity of green bio-molecule, ascorbic acid towards an aqueous solution containing $\mathrm{Ag}^{+}$and $\mathrm{Fe}^{3+}$ ions (reduction potential $=+0.799 \mathrm{~V}$ and $-0.04 \mathrm{~V}$ for $\mathrm{Ag}^{+} / \mathrm{Ag}^{0}$ and $\mathrm{Fe}^{3+} /$ $\mathrm{Fe}^{0}$, respectively). To the best of our knowledge, CTABprotected Ag@Fe NPs were prepared for the first time using this competitive approach between the two metal ions. The $\mathrm{Ag} @ \mathrm{Fe}$ NPs were used as catalyst for the first time in reduction of methyl orange with an aqueous $\mathrm{NaBH}_{4}$ as a reducing agent at room temperature.

\section{Experimental}

\section{Materials}

The stock solution of all reagents was prepared by deionized, $\mathrm{CO}_{2}$ - free or doubly distilled water of specific conductance $(1-2) \times 10^{-6} \mathrm{O}^{-1} \mathrm{~cm}^{-1}$ as a solvent. Iron(III) nitrate hexahydrate $\left(\mathrm{FeNO}_{3} \cdot 6 \mathrm{H}_{2} \mathrm{O}\right.$, molar mass $=349.94,99 \%$, $\mathrm{BDH})$, silver nitrate $\left(\mathrm{AgNO}_{3}\right.$, molar mass $=169.87,99.9 \%$, $\mathrm{BDH})$, cetyltrimethylammonium bromide $\left(\mathrm{C}_{19} \mathrm{H}_{42} \mathrm{BrN}\right.$, molar mass $=364.45,99 \%), \mathrm{BDH})$, ascorbic acid $\left(\mathrm{C}_{6} \mathrm{H}_{6} \mathrm{O}_{8}\right.$, molar mass $=176.12,99.5 \%, \mathrm{BDH})$, nitric acid $\left(\mathrm{HNO}_{3}\right.$, $1 \mathrm{M})$, hydrochloric acid ( $\mathrm{HCl}, 36 \mathrm{wt} \%)$, and methyl orange $\left(\mathrm{C}_{14} \mathrm{H}_{14} \mathrm{~N}_{3} \mathrm{NaO}_{3} \mathrm{~S}\right.$; formula weight $\left.=327.33\right)$ were used as received. The preparation of ascorbic acid on daily basis was followed by boiled and cooled water treatment to control the aerial oxidation. The purity of CTAB was tested by the absence of minima in surface tension versus log [CTAB] plots (Harrold 1960).

\section{Synthesis and characterization of Ag@Fe composites}

Size- and shape-controlled synthesis of Ag-Fe nanocomposites was carried out in a typical experiment, in which ascorbic acid $\left(0.01 \mathrm{~mol} \mathrm{dm}^{-3} ; 5.0 \mathrm{~cm}^{3}\right)$ was added in a solution of $\mathrm{Fe}\left(\mathrm{NO}_{3}\right)_{3}+\mathrm{AgNO}_{3}+\mathrm{CTAB}$ containing $0.01 \mathrm{~mol} \mathrm{dm}^{-3}$; $5.0 \mathrm{~cm}^{3}$ of each reagent. The optimized conditions for the stable and rapid synthesis will help in large-scale synthesis of monodispersed Ag@Fe NPs. The current research work investigates the findings of optimization of different experimental variables like silver nitrate concentration, surfactant concentration, reaction time, temperature, and pH on $\mathrm{Ag} @$ $\mathrm{Fe}$ core/shell NPs. The color change of the solution was observed and the absorbance of resulting solutions was monitored UV-Vis spectrophotometrically. It is well known that $\mathrm{AgNO}_{3}$ has higher reduction potential $(0.8 \mathrm{~V})$ and, therefore, is more easily reduced as compared to $\mathrm{Fe}\left(\mathrm{NO}_{3}\right)_{3}$ with lower reduction potential $(0.77 \mathrm{~V})$. Scheme 1 describes the possible formation mechanism of Ag@Fe NPs. 


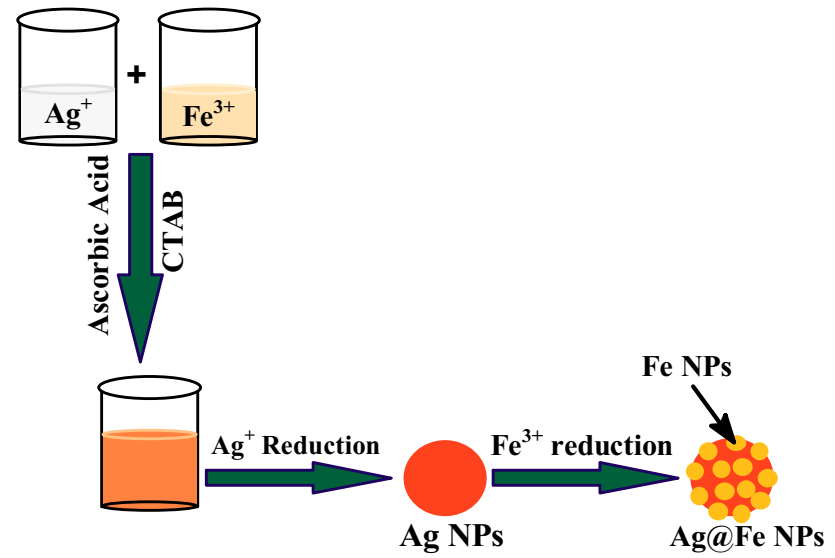

Scheme 1 Schematic illustration of seedless formation mechanism of Ag@Fe NPs

The formation of Ag@Fe nanoparticles is observed from the reaction color change from colorless to dark yellow with course of time (Al-Thabaiti et al. 2017). The dark yellow color reaction mixture was centrifuged at $1000 \mathrm{rpm}$ for $15 \mathrm{~min}$ for further characterization. The purification of particles to remove impurities was achieved by re-suspend them in water and centrifugation was repeated twice. The as-acquired material was further washed several times with deionized water to remove excess CTAB and other unwanted materials. The spectrophotometer UV-260 Shimadzu was used to obtain UV-visible spectra of different solutions with $1 \mathrm{~cm}$ quartz cuvettes at 200-800 nm. The morphology of as-prepared $\mathrm{Ag} @ \mathrm{Fe}$ nanoparticles was determined using transmission electron microscope (TEM) (JEOL, JEM-1011; Japan) equipped with energy dispersion X-ray spectroscopy (EDX) TECHNAI-320 kV Japan, operating at $80 \mathrm{kV}$. For TEM measurements, samples were prepared by placing a drop of working solution on a carbon-coated standard copper grid (300 meshes). The X-ray diffraction (XRD) analysis was carried out on an X-ray diffractometer using $\mathrm{Ni}$-filtered $\mathrm{Cu} \mathrm{K} \alpha$ radiation $(\lambda=1.54056$ $\AA$ ) Rigaku X-ray diffractometer operating at $40 \mathrm{kV}$ and $150 \mathrm{~mA}$ at a scanning rate of 0.020 per step in the $2 \theta$ range of $100 \leq 2 \theta \leq 800$. An Accumet, Fisher Scientific digital $\mathrm{pH}$ meter 910 fitted with a combination electrode was used for $\mathrm{pH}$ measurements. Fourier-transform infrared (FTIR) spectra were recorded on an IR Prestige-21, IR Affinity-1, FTIR-8400S (Shimadzu Corporation Analytical and Measuring Instrument Division) using a $\mathrm{ZnSe}$ cell at room temperature $\left(28-30{ }^{\circ} \mathrm{C}\right)$ in the wavelength range of $4000-400 \mathrm{~cm}^{-1}$. A few drops of sols were placed on a $\mathrm{KBr}$ pellet and allowed to dry before FTIR spectra were recorded.

\section{Determination of critical micelle concentration (cmc)}

The conductivity was measured by assembly of conductivity meter (AC-13 Japan) and a conductivity cell (cell constant $0.943 \mathrm{~cm}^{-1}$ ). The conductivity meter was calibrated with $\mathrm{KCl}$ solution and a thermostat was maintained by circulating water through the outer jacket of the cell as to maintain the constant temperature at $\pm 0.01 \mathrm{~K}$. The titrated surfactant with changing specific conductivity at $25^{\circ} \mathrm{C}$ in an aqueous solution was used to determine $\mathrm{cmc}$ values of surfactant. The cmc values were obtained by the break points of two nearly straight lines in a specific conductivity versus concentration plots. The influence of foreign ions is well influenced with the degree of ionization of micelles. However, the experimental methodologies have an imminent role towards the uncertainties in the cmc values. The overall increased conductivity values of the studied range through an electric conductivity method are behind the presence of charged and conductive ionic species of solution. Thus, the effect of $\mathrm{cmc}$ values may result because of the presence of foreign ionic species, and may in turn have an influence upon the degree of ionization of the surfactant micelles. The different experimental conditions in an aqueous solution of $\left(\mathrm{CTAB}+\mathrm{H}_{2} \mathrm{O}\right.$, $\mathrm{CTAB}+$ ascorbic acid and CTAB + Ag@Fe NPs) were interpreted as a mean of surfactant concentration break points in a plot of specific conductance versus surfactant concentration conductometrically. The pre-micellar and post-micellar regions of micellization were linearly correlated [surfactant] with slope greater than in latter region. The accuracy of $\pm 1 \%$ was found during the conductance measurements.

\section{Catalytic activity of Ag@Fe}

It is well known that metal nanoparticles have potential to catalyze some chemical reactions that are not achievable. The size, shape, and composition of nanoparticles play an important role in the catalytic reactions. The catalytic activity of as-prepared $\mathrm{Ag} @ \mathrm{Fe}$ bimetallic nanoparticles was assessed against methyl orange toxic dye as a substrate by $\mathrm{NaBH}_{4}$. Batch experiments were conducted to understand the mechanism for the degradation of MO dyes using Ag@ Fe core/shell NPs at room temperature. All the experiments were performed in an open-batch system at neutral $\mathrm{pH}$ and room temperature. The experimental conditions adopted throughout the whole investigation were $1.0 \times 10^{-4}$ mol dm ${ }^{-3}$ concentration for MO dyes, $1.6 \times 10^{-3} \mathrm{~mol} \mathrm{dm}^{-3}$ of $\mathrm{Ag} @ \mathrm{Fe}$ nanocatalyst, $\mathrm{NaBH}_{4} 1.0 \times 10^{-3} \mathrm{~mol} \mathrm{dm}^{-3}$, and temperature of $25.0 \pm 0.2{ }^{\circ} \mathrm{C}$. A UV-260 Shimadzu, with $1 \mathrm{~cm}$ quartz cuvettes UV-visible spectrophotometer, was used to monitor the methyl orange reduction by Ag@ Fe bimetallic nanocomposite in the range of $200-800 \mathrm{~nm}$ wavelengths. In a typical experiment, resulting Ag@Fe NPs 
$\left(=1.6 \times 10^{-4} \mathrm{~mol} \mathrm{dm}^{-3}\right)$ were mixed with aqueous solution of methyl orange dye $\left(1.0 \times 10^{-4} \mathrm{~mol} \mathrm{dm}^{-3}\right)$ at room temperature under continuous stirring for at least $20 \mathrm{~min}$. We did not observe any significant decay at $464 \mathrm{~nm}\left(\lambda_{\max }\right.$ of methyl orange). A solution of $\mathrm{NaBH}_{4}\left(=1.0 \times 10^{-3} \mathrm{~mol} \mathrm{dm}^{-3}\right)$ was added into the reaction vessel under continuous stirring. A clear change in the absorbance of methyl orange with the reaction time was observed, indicating the reduction of methyl orange dye by Ag@Fe NPs in the presence of $\mathrm{NaBH}_{4}$. The degradation efficiency $(\% D)$ was calculated using Eqs. $(2,3)$ :

Degradation $(\%)=\frac{C_{0}-C}{C_{0}} \times 100$,

Degradation $(\%)=\frac{A_{0}-A_{\mathrm{t}}}{A_{0}} \times 100$,

where $C_{0}$ is the initial concentration of MO dye and $C$ is the concentration of $\mathrm{MO}$ dye after degradation at particular time intervals. $A_{0}$ is the absorbance of the MO dye solution before degradation and $A_{\mathrm{t}}$ is the MO dye absorbance after certain time $t$. Recyclability tests for MO dye degradation were carried out by separating Ag@Fe NPs from the reaction mixture by an external magnet after MO dye had completely degraded. The separated Ag@Fe NPs were washed three times with deionized water before the next catalytic reaction was performed.

\section{Results and discussion}

\section{TEM, FTIR, XRD, and EDX}

Figure 1 shows electron microscope images of $\mathrm{Ag} @ \mathrm{Fe}$ bimetallic NPs obtained by the $\mathrm{Ag}^{+}+\mathrm{Fe}^{3+}+$ ascorbic acid redox systems. Interestingly, Fig. 1 shows the formation of a big nanocluster of Ag @ Fe (diameter=ca. $108 \mathrm{~nm}$ ). Inspection of TEM images clearly indicates that the various tiny nanoparticles try to adsorb onto the surface of bulky nanoparticles, which might be due to the higher reactivity of $\mathrm{Fe}$ metal towards less active Ag. The particles are distributed non-uniformly with an irregular shape. The resulting NCPs are body centered cubic $\mathrm{Fe}$ with a protective a layer of dehydroascorbic acid and/or CTAB encapsulating the particles and preventing oxidation. These results are in accordance with the observations of Carroll et al. (2010a, b) regarding the one-pot aqueous synthesis of $\mathrm{Fe}$ and $\mathrm{Ag}$ core/shell nanoparticles, which were encapsulated by a citrate layer.

The IR of pure ascorbic acid and CTAB shows the main characteristic peaks at 3200-3500, 1764, 1680, and $1324 \mathrm{~cm}^{-1}$, and 2923, 2851, 1490, and $1426 \mathrm{~cm}^{-1}$, which are attributed to the different $-\mathrm{OH}$ groups, $\mathrm{C}=\mathrm{O}$ five membered lactone ring, $\mathrm{C}=\mathrm{C}$, enol- $\mathrm{OH}$ and $\mathrm{CH}_{2}$ stretching, antisymmetric deformation of alkyl chain, and $\mathrm{C}-\mathrm{N}$ stretching, respectively (Fig. 2). In Ag@Fe NPs, the peaks of ascorbic acid at 1680 and $1324 \mathrm{~cm}^{-1}$ disappeared completely, and new peaks were observed at 3344, 1738, and $1645 \mathrm{~cm}^{-1}$, which might be due to the dehydroascorbic acid (oxidation product of ascorbic acid) (Xiong et al. 2011; Al-Thabaiti et al. 2015). On the other hand, peaks of CTAB shifted from 2923, 2851, and $1490 \mathrm{~cm}^{-1}$, and 1426-2910, 2846, $1414 \mathrm{~cm}^{-1}$, and $1124 \mathrm{~cm}^{-1}$, respectively (Fig. 2), and peaks intensity also decreased. Thus, we may state confidently that the resulting Ag@Fe NPs stabilized and/or coated by both CTAB and dehydroascorbic acid, which prevent their oxidation with water and/or dissolved oxygen in an aqueous solution.

X-ray diffraction patterns of pure AgNPs, FeNPs, and $\mathrm{Ag} @ \mathrm{Fe}$ NPs are summarized in Fig. 3. All major diffraction peaks at $39.2^{0}, 44.4^{0}, 64.4$, and $78.2^{0}$ corresponding to the $\{111\},\{200\},\{220\},\{311\}$ crystalline plane of
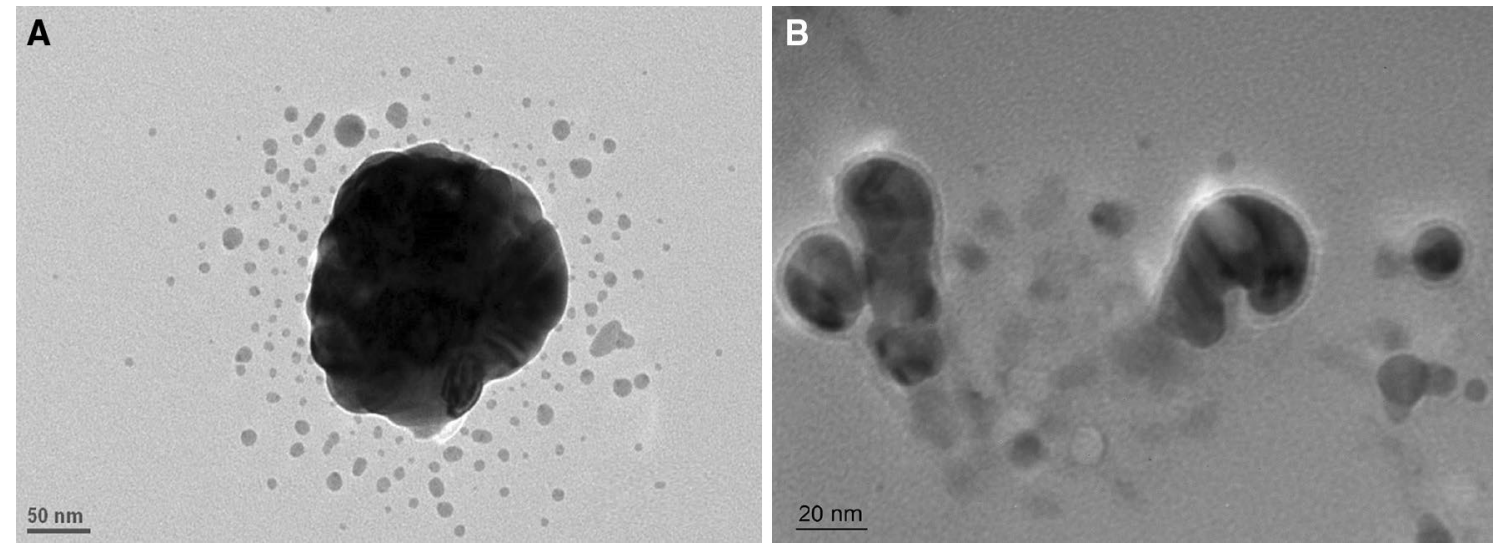

Fig. 1 TEM images of Ag@Fe nanocomposites. Reaction conditions: $\left[\mathrm{Fe}^{3+}\right]=10.0 \times 10^{-4} \mathrm{~mol} \mathrm{dm}^{-3},[\mathrm{CTAB}]=10.0 \times 10^{-4} \mathrm{~mol} \mathrm{dm}^{-3}$, $[$ ascorbic acid $]=10.0 \times 10^{-4} \mathrm{~mol} \mathrm{dm}{ }^{-3}$, and $\left[\mathrm{Ag}^{+}\right]=2.0 \times 10^{-4} \mathrm{~mol} \mathrm{dm}^{-3}$ 


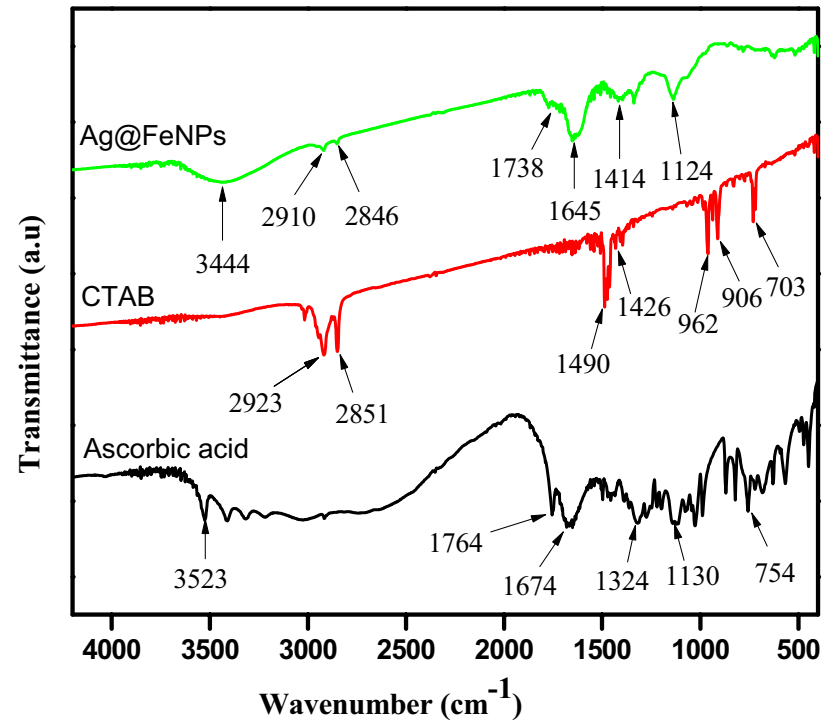

Fig. 2 FT-IR spectra of ascorbic acid, CTAB and Ag@FeNPs. Reaction conditions: the same as Fig. 1

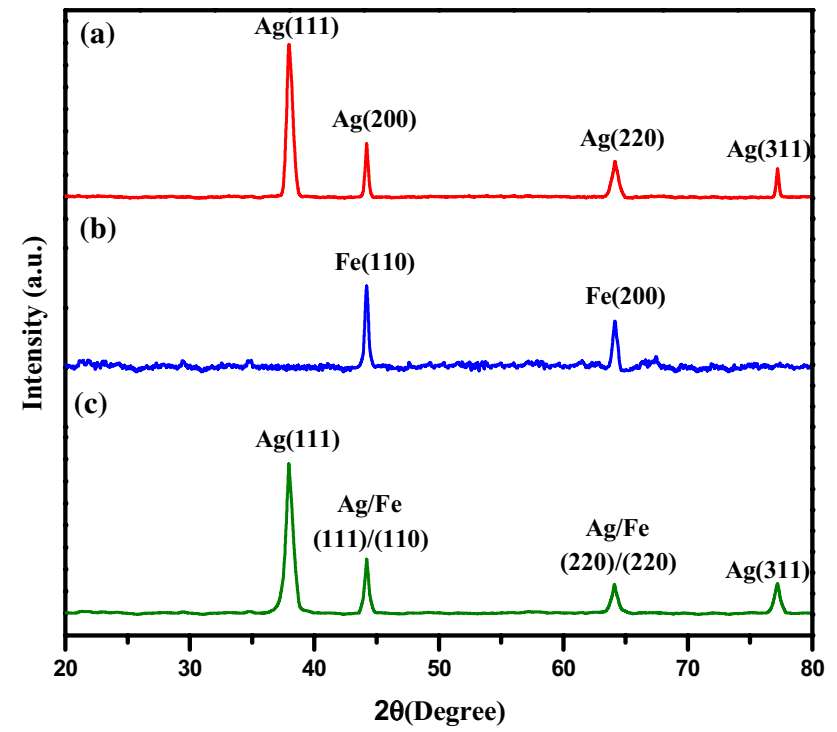

Fig. 3 XRD data of AgNPs, FeNPs, and Ag@Fe NPs. Reaction conditions: the same as Fig. 1

the $\mathrm{Ag}, 44.2^{0}\{110\}, 64.4\{200\}$ for $\mathrm{Fe}$, and $39.2^{0}, 44.4^{0}$, $64.4^{0}, 78.2^{0}$ corresponding to the $\{111\} \mathrm{Ag},\{220\} / 220$ $\mathrm{Ag} / \mathrm{Fe},\{64.4\} \mathrm{Ag} / \mathrm{Fe},\{311\} \mathrm{Ag}$. The EDX and chemical analysis indicate the existence of $\mathrm{Ag}, \mathrm{Fe}$, and $\mathrm{O}$ elements in our sample (Fig. 4). The peak at around $3 \mathrm{keV}$ and 1 , 6-7 keV in the EDX spectrum is the characteristic feature of metallic Ag and Fe. Similar type of peak at $3.2 \mathrm{keV}$ was found in the EDX spectra confirming the formation of $\mathrm{Ag} @ \mathrm{Fe}$ NPs. The presence of O peak in EDX confirmed that some $\mathrm{Fe}$ has been oxidized into the corresponding oxides; however, complete oxidization of $\mathrm{Fe}$ to its different

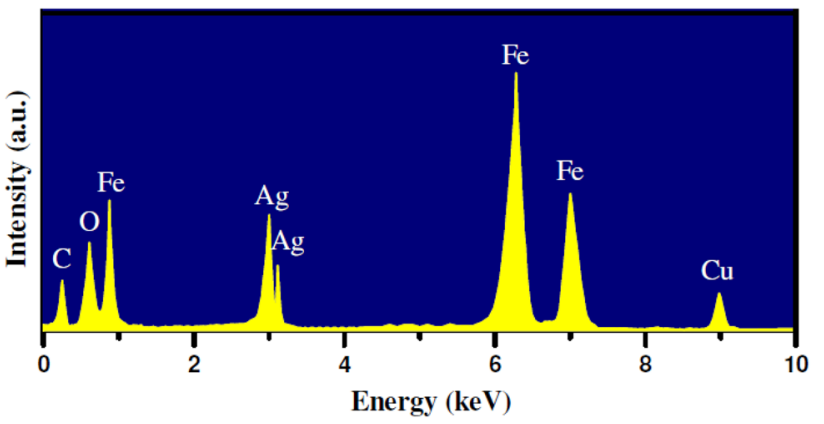

Fig. 4 EDX data of Ag@Fe NPs. Reaction conditions: the same as Fig. 1

oxidation forms was restricted under our experimental condition.

\section{Role of CTAB}

The amphiphilic molecules, for instance, surfactants in an aqueous media aggregate at a specific concentration, form dynamic aggregates or micelles. The versatile properties like nature of head group, the presence of counter ions, and length of hydrophobic tale of surfactants are responsible to alter the shape, size, and other surface morphologies and optical properties of nanoparticles to different extents (Pal et al. 1997). The amphiphilic molecules upon the narrow range of concentration called critical micelle concentration (cmc) undergo an abrupt change in their physicochemical properties. The above critical concentration has a direct influence on the physical and chemical properties of the surfactant solution. The process of micellization is effective on account of attractive or repulsive responses of counterions and, thus, tends to increase the rate of reaction. The rate of reaction is affected by incorporation of substrate into micellar aggregates rather than by changing the solvent properties of water. The prime factors responsible for the rate enhancement of the biomolecular reactions are the hydrophobic, hydrogen bonding, and electrostatic interactions. Beside, the frequency of molecular collisions at the micellar interface enhances as a result of close associations between two reacting species. At an appropriate [CTAB], Sihai and David fabricated two-dimensional silver nanoplates by chemical method (Sihai and David 2004). Similarly, in the presence of CTAB, Sau and Murphy have synthesized gold nanoparticles of multiple shapes and morphologies (Sau and Murphy 2004). On the other hand, by adjusting [CTAB], Yu and Yam reported a modified silver mirror reaction method for the synthesis of silver nanoparticles of various morphologies (Yu and Yam 2005).

It has been established that the pure Fe NPs are very unstable and/or very reactive towards atmospheric oxygen $\left(\mathrm{O}_{2}\right)$ and very fast oxidized to iron oxides in aqueous reaction 
mixture and the available reach of vicinal water (Laurent et al. 2008). Therefore, choice of choosing the best stabilizer is a vital problem that we take in consideration first. To see insight into the role of CTAB, a series of UV-visible spectra of only $\mathrm{Fe}\left(\mathrm{NO}_{3}\right)_{3}=10.0 \times 10^{-4} \mathrm{~mol} \mathrm{dm}{ }^{-3}, \mathrm{Fe}\left(\mathrm{NO}_{3}\right)_{3}+$ ascorbic acid, $\mathrm{Fe}\left(\mathrm{NO}_{3}\right)_{3}+\mathrm{AgNO}_{3}+$ ascorbic acid, and $\mathrm{AgNO}_{3}+$ ascorbic acid were recorded in the absence and the presence of CTAB. UV-visible spectroscopy has been accepted as one among most utilized techniques for characterization of water-soluble metal NPs (Henglein 1993; Lina et al. 2014). Figure $S 1$ (supporting information) is addressed towards the sharp absorption peak of $\mathrm{Fe}^{3+}$ ions at ca. $350 \mathrm{~nm}$ (black color line), whereas in the presence of ascorbic acid the spectra, show drastic changes. The peak disappeared completely (Figure S1; red color line). The absence of peak at $350 \mathrm{~nm}$ corresponding to unreduced $\mathrm{Fe}^{3+}$ ions implies that the metal ions are completely reduced to $\mathrm{Fe}^{0}$ by ascorbic acid (Hoag et al. 2009). While analyzing the spectra, we were not able to observe the appearance of any distinguishable peak and/or broad shoulder in the entire UV-visible spectral region for $\mathrm{Ag} @ \mathrm{Fe}$ and the resulting sols is colorless. On the other hand, spectra $\mathrm{Ag}^{+}$ions + ascorbic acid are also featureless (no peak in the visible region (Figure S1; gray color line). However, the spectra of reaction mixture containing $\mathrm{Fe}\left(\mathrm{NO}_{3}\right)_{3}+\mathrm{AgNO}_{3}+$ ascorbic acid show the three peaks at 300, 352 and $450 \mathrm{~nm}$ having very weak intensity, which might be due to the formation of FeNPs and Ag@ Fe core-shell NPs. All the different curves have the first absorption peaks around at $300 \mathrm{~nm}$ analogous behind the oxidation product of ascorbic acid, i.e., dehydroascorbic acid (Lai et al. 2013).

The spectra of pale yellow sols show two shoulders at 300 and $352 \mathrm{~nm}$ (Fig. 5; green color line). The shoulder at $352 \mathrm{~nm}$ which might be due to the formation of Fe NPs in pristine form, i.e., $\mathrm{Fe}^{0}$ (collective oscillation of the surface plasmons), and is pale yellow in color. These results (broad peak at $352 \mathrm{~nm}$ ) find an appropriate relevance with the observations of Siwach and Sen 2008 and Guo et al. 2001 regarding the UV-visible spectra of the pure Fe NPs' dispersion in water. On the other hand, a well-defined sharp peak appeared at $430 \mathrm{~nm}$ in a solution of $\mathrm{Fe}\left(\mathrm{NO}_{3}\right)_{3}+\mathrm{AgNO}_{3}+$ ascorbic acid and colorless reaction mixture became dark brown (Fig. 5; blue color line), which can be rationalized by considering the incorporation and/or solubilization of reactants $\left(\mathrm{Fe}^{3+}\right.$ ions, $\mathrm{Ag}^{+}$ions, and ascorbic acid) and product, $\mathrm{Ag} @ \mathrm{Fe}$ into the Stern layer of CTAB micelles through electrostatic, hydrophobic, and van der Walls interactions.

Optical images of the same reaction mixture containing $\mathrm{Fe}^{3+}+$ ascorbic acid (A), $\mathrm{Fe}^{3+}+\mathrm{Ag}^{+}$(B), and $\mathrm{Fe}^{3+}+\mathrm{Ag}^{+}+$ascorbic acid (C) are also given in Figure S2 as supporting information, indicating the appearance pale gray, colorless, and pale yellow turbidity. Interestingly, optical images of these reaction mixtures show that the

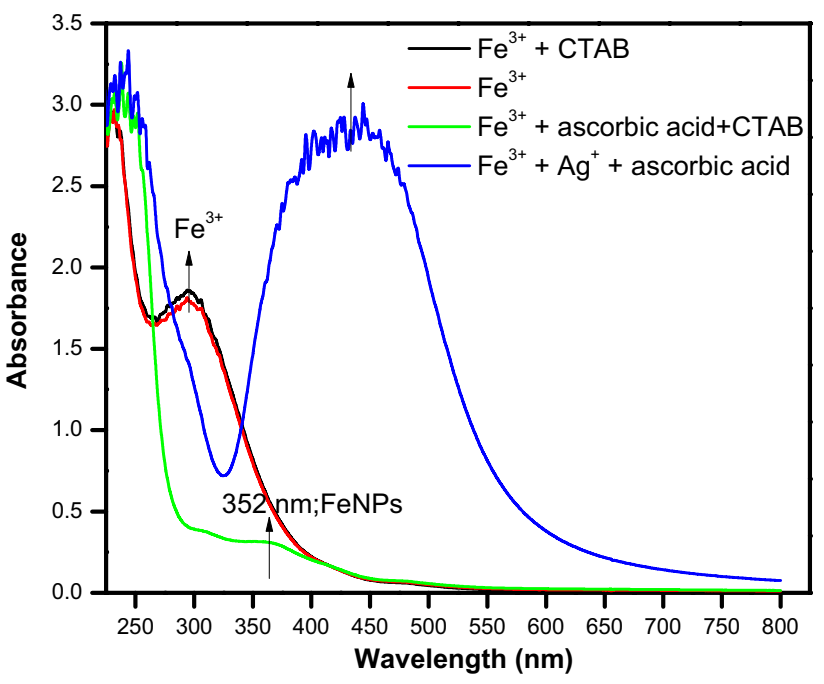

Fig. 5 Effects of CTAB on the UV-visible spectra of $\mathrm{Fe}\left(\mathrm{NO}_{3}\right)_{3}$ aqueous solution, $\mathrm{Fe}\left(\mathrm{NO}_{3}\right)_{3}+$ ascorbic acid, and $\mathrm{Fe}\left(\mathrm{NO}_{3}\right)_{3}+\mathrm{AgNO}_{3}+$ ascorbic acid at room temperature. Reaction conditions: $\left[\mathrm{Fe}^{3+}\right]=10.0 \times 10^{-4}$ mol $\mathrm{dm}^{-3}$, [ascorbic acid $]=10.0 \times 10^{-4} \mathrm{~mol} \mathrm{dm}{ }^{-3},\left[\mathrm{Ag}^{+}\right]=10.0 \times 10^{-4} \mathrm{~mol} \mathrm{dm}{ }^{-3}$, and $[\mathrm{CTAB}]=10.0 \times 10^{-4} \mathrm{~mol} \mathrm{dm}^{-3}$

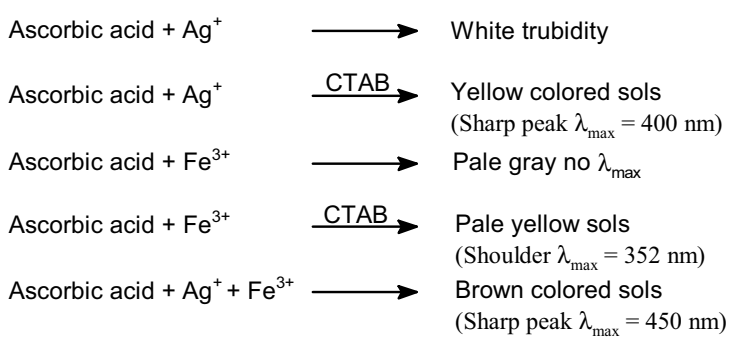

Scheme 2 Preliminary observations regarding the role of CTAB

prefect transparent yellow color appeared in the presence of CTAB (Figure $\mathrm{S} 3$; supporting information: only $\left[\mathrm{Fe}^{3+}\right]$ (A), $\left[\mathrm{Fe}^{3+}\right]+[\mathrm{CTAB}](\mathrm{B}),\left[\mathrm{Fe}^{3+}\right]+[\mathrm{CTAB}]+[$ ascorbic acid $](\mathrm{C})$, and $\left[\mathrm{Fe}^{3+}\right]+[\mathrm{CTAB}]+[$ ascorbic acid $]+\left[\mathrm{Ag}^{+}\right]$ (D) for $\left[\mathrm{Fe}^{3+}\right]=10.0 \times 10^{-4} \mathrm{~mol} \mathrm{dm}{ }^{-3},[\mathrm{CTAB}]=10.0 \times 10^{-4}$ mol dm${ }^{-3}$, [ascorbic acid] $=10.0 \times 10^{-4} \mathrm{~mol} \mathrm{dm}^{-3}$, and $\left[\mathrm{Ag}^{+}\right]=2.0 \times 10^{-4} \mathrm{~mol} \mathrm{dm}{ }^{-3}$ ), which might be due to the shape-controlling and solubilization effects of CTAB micelles. Overall observations are summarized in Scheme 2.

Depending on the basis results obtained, we may state confidently that the CTAB concentrates the reactants (ascorbic acid, $\mathrm{Fe}^{3+}$, and $\mathrm{Ag}^{+}$ions), protects the resulting nanomaterials, controlled the unlimited growth, and inhibits their simultaneous oxidation (corrosion) with dissolved atmospheric oxygen and/or water. As a result, stable Ag@Fe NPs are formed at room temperature under our experimental conditions. $\mathrm{Wu}$ and his co-workers also reviewed the same observations, role of surfactants as coating materials, which 
protects the resulting NCPs from the oxidation in an aqueous solution (Wu et al. 2015).

The process of agglomeration or uncontrolled fabrication of stable and well-dispersed nanoparticles in aqueous solution can be prevented using CTAB as a stabilized for nanoparticle synthesis. However, during the synthesis process of nanoparticles, the thermo-migration of nanoparticles shows some sort of agglomeration because of nanoparticle exhaustion. The formation of micelles was affirmed via the determination of $\mathrm{cmc}$ by a conventional conductometric method at $25{ }^{\circ} \mathrm{C}$ (Fig. 6). The observed cmc values of CTAB in the presence of aqueous ascorbic acid solution were found to be lower as compared to the cmc values of CTAB in pure water. The similar results have been observed and reported for CTAB in the presence of glycine (Koya et al. 2015). The cmc of CTAB in water is decreased in the presence of ascorbic acid as it increases screening by means of electrostatic interaction between head groups (positively charged) of the surfactant molecules, in turn the micelle formation results at lower concentration with the energetically favorable aggregate structures. The cmc values of CTAB in water were found to be $9.9 \times 10^{-4} \mathrm{~mol} \mathrm{dm}^{-3}$ and were compared with the cmc value of $\mathrm{CTAB}$ in the presence of the ascorbic acid $\left(9.0 \times 10^{-4} \mathrm{~mol} \mathrm{dm}^{-3}\right)$ and Ag@Fe NPs $\left(8.2 \times 10^{-4}\right.$

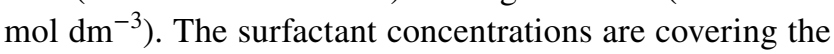
range below and above cmc. The lower values of $\mathrm{cmc}$ than in water imply that the active species of $\mathrm{Ag} / \mathrm{Fe}$ precursors interact with positive head group of CTAB aggregates and submicellar aggregates may be formed which brings the reactants together through electrostatic interactions. Once the reduction process starts bringing $\mathrm{Ag}^{+}$to $\mathrm{Ag}^{0}$ and $\mathrm{Fe}^{3+}$ to $\mathrm{Fe}^{0}$, the cmc value decreases for CTAB micelles, and the

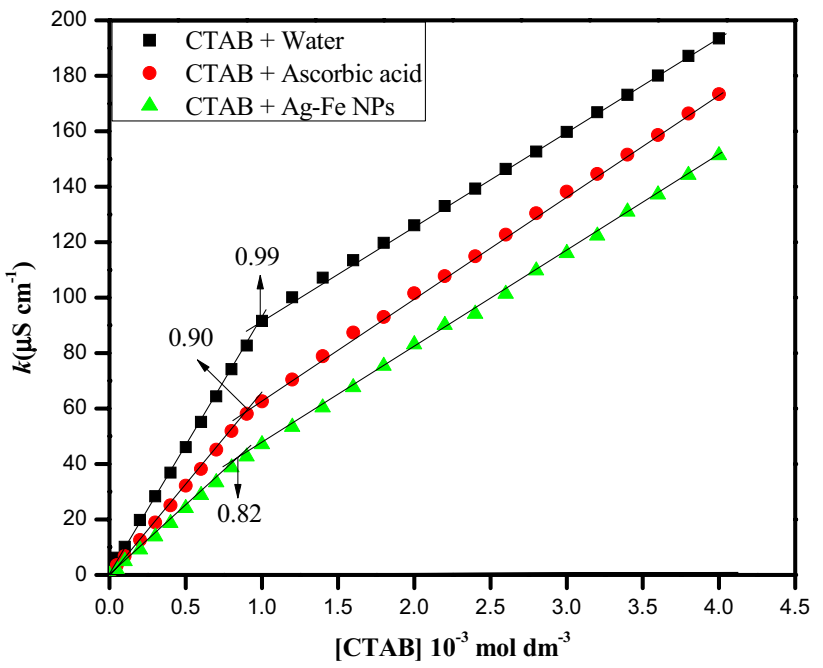

Fig. 6 Plot of specific conductivity versus surfactant (CTAB) concentration in water $(\mathrm{CTAB}+$ water) and in the presence of ascorbic acid and Ag@Fe NPs (CTAB + ascorbic acid, CTAB + Ag@Fe NPs) said reduction process is also arresting the growth of particle size and stabilization of the synthesized Ag@Fe NPs. The obtained cmc values are dependent on the degree of ionization of surfactant micelles which may be interfered by the presence of foreign ionic species and, therefore, results in color change in the nanosol and also leads to a spectral shift in SPR band of as-synthesized Ag@Fe NPs. We observe that $\lambda_{\text {max }}$ of SPR peak intensity increases faster as the CTAB concentration increases. This mans that $\mathrm{Ag}$ nanoparticle formation rate is comparatively faster in the presence of CTAB with broadening in the absorption bandwidth (Fig. 7). The broadening and red shift in SPR band with [CTAB] specify that primarily reduced AgNPs grow to form larger particles and the Fe nanoparticles are well stabilized and protected to oxidize by the CTAB micelles and reduced on the surface of the Ag NPs forming shell around the Ag nanocore. The head group size and the charge of the surfactant is one the factors that chose the adsorption of the surfactant monomers, dimmers, and trimmers onto the surface of the synthesized nanoparticles; therefore, a difference of interactions between positively charged head group of CTAB and negatively charged surface of the synthesized nanoparticles. These related parameters have an obvious affect upon adsorption of monomers or micelle surfactant onto Ag@Fe NPs, and consequently, influence the nanoparticle's size and color formation changes. The pre- and post-micellar effects on the growth, stability, and color of silver nanoparticles can be rationalized by considering the distribution and/or solubilization of the reactants among the different pseudo-phases present in the reaction medium. The reaction rates decrease with increasing [CTAB] which may be due to the dilution

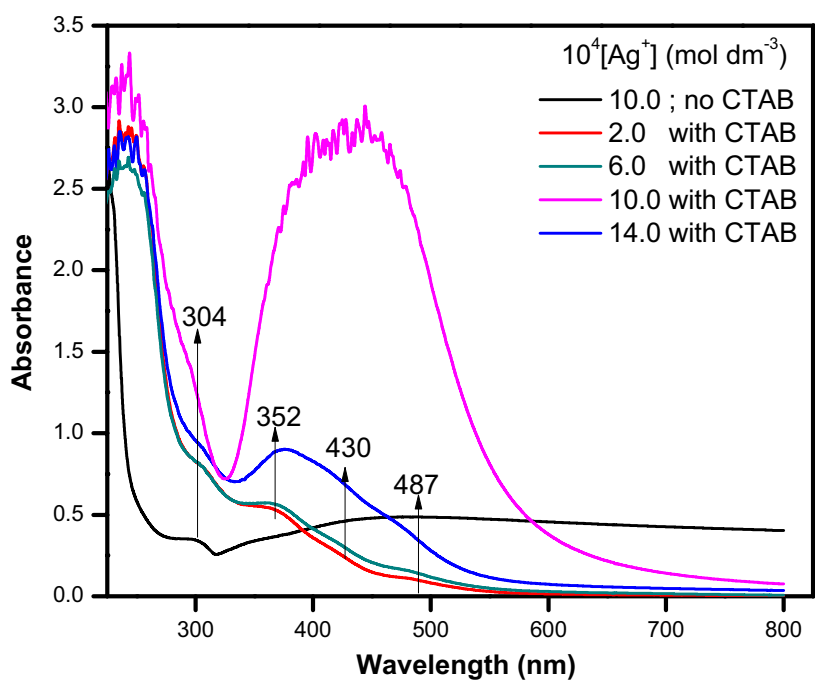

Fig. 7 Effects of $\left[\mathrm{Ag}^{+}\right]$on the UV-visible spectra of $\mathrm{Ag} @ \mathrm{Fe}$ nanocomposites in the absence and the presence of CTAB at room temperature. Reaction conditions: $\left[\mathrm{Fe}^{3+}\right]=10.0 \times 10^{-4} \mathrm{~mol} \mathrm{dm}{ }^{-3}$, [ascorbic acid $]=10.0 \times 10^{-4} \mathrm{~mol} \mathrm{dm}^{-3}$, and $[\mathrm{CTAB}]=10.0 \times 10^{-4} \mathrm{~mol} \mathrm{dm}^{-3}$

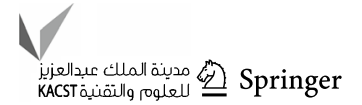


effect: a continuous increase in [CTAB] produces micelles, and progressively, more and more ascorbic acid (mild reducing agent) gets incorporated into the Stern layer (most of the ionic micelle-mediated reactions are believed to occur in this region and polarity of the Stern layer is generally considered to be lower than the bulk water). In general, when more other solutes are dissolved in water, the $\mathrm{cmc}$ of a surfactant will become smaller, because less water molecules are available for the surfactant molecules, or in other words, the water is more hydrophobic than before the addition of the solutes. Typically, when a salt or a relatively hydrophobic polymer is added, the cmc of the surfactant will decrease remarkably. To get insights into the sub- and post-micellar roles of shape-directing CTAB, a series of experiments were performed at different $[\mathrm{CTAB}]$ and fixed concentrations of other reagents.

[CTAB] below cmc: The CTAB in an aqueous solution show critical micellar concentration $(\mathrm{cmc})$ at $\sim 0.99 \times 10^{-3}$ mol $\mathrm{dm}^{-3}$, and the monomers of CTAB are believed to associate at or above this surfactant concentration to form micelles. At CTAB concentration less than $5.0 \times 10^{-4}$ $\mathrm{mol} \mathrm{dm}{ }^{-3}$, the addition of a reducing agent as a ascorbic form the black precipitate, but when the CTAB concentration was higher than $5.0 \times 10^{-4} \mathrm{~mol} \mathrm{dm}^{-3}$, i.e., below $\mathrm{cmc}$, a transparent yellow sol indicated the Ag@Fe formation. During nanoparticle formation, the molecules of CTAB as stabilizer get adsorbed on the nanoparticle surfaces. However, at low [CTAB], i.e., less than $\mathrm{cmc}$, the number of CTAB molecules is insufficient to form a continuous adsorption layer on the surface of the nanoparticles. It is well established that at $[\mathrm{CTAB}]$ even less than $\mathrm{cmc}$, there are enough CTAB molecules to stabilize the Ag@Fe NPs and inhibit their aggregation. This is also conformed by the appearance of yellow color and a peak at $450 \mathrm{~nm}$ in the absorption spectra. The shape and size of the Ag@Fe nanoparticles depend on the concentrations of surfactant, reagents, synthesis temperature, and other experimental conditions. All the parameters were found to be interdependent. Among the various parameters, the relative concentrations of CTAB and metal ion concentration are particularly crucial for the control of both the morphology and the size of Ag@Fe nanoparticles.

[CTAB] above CMC: The stable Ag@ Fe NPs' formation was observed mostly above cmc of CTAB. [CTAB] was varied in range between 1.0 and $4.0 \times 10^{-4} \mathrm{~mol} \mathrm{dm}^{-3}$ to observe the color variations and the spectral changes with $\mathrm{CTAB}$ concentrations in reaction mixture. The $450 \mathrm{~nm}$ peak was generally centered in surface plasmon, although the peak intensity was affected by the CTAB and as well as Ag ion concentrations. It was clearly observed that at [CTAB]-cmc, stable nearly monodisperse Ag@ $\mathrm{Fe}$ NPs were formed with a distinctive $450 \mathrm{~nm}$ plasmon absorption peak. At $\mathrm{cmc}$ and above cmc, the $\mathrm{Ag}^{+} / \mathrm{Fe}^{3+}$ ions reside in the periphery of CTAB-spherical micelles formed by the aggregations of
CTAB monomers. The reason behind the micellization is availability of higher local concentration of counter ions, i.e., $\mathrm{Br}^{-}$at the micelle surface. The presence of large number of $\mathrm{Ag}^{+} / \mathrm{Fe}^{3+}$ ions in this region is due to the electrostatic attraction; as a result, multiple reduction processes take place to form the stable $\mathrm{Ag} @ \mathrm{Fe}$ nanoparticles in the micellar periphery. The availability of high local concentration of precursor ions results in the formation of $\mathrm{Ag} @ \mathrm{Fe}$ nanoparticles, and in addition, the local micellar environment in the region prevents the oxidation of $\mathrm{Fe}$ nanoparticles on the surface of the Ag core. The non-polar chain of CTAB interacts with the hydrophobic layer around the nanoparticles, and as a result, the polar groups from CTAB are facing out, stabilizing the particles in aqueous media. Thus, even a high metal ion concentration, at or above, the cmc of the surfactant concentrations may be used for stable nanoparticle preparation. Here, the black precipitation was not observed at low [CTAB] which concludes that the formation of Ag@Fe NPs varies for the low and high [CTAB]. It clearly demonstrates that the CTAB catalytic effect is not only above, but also even below the cmc (i.e., micellar as well as pre-micellar catalyzes are observed).

\section{Role of $\left[\mathrm{Ag}^{+}\right]$}

The optical properties of the nanoparticles were investigated by UV-visible spectra. It is well known that the surface plasmon resonance is the coherent excitation of free electrons within the conduction band, leading to an inphase oscillation. To get quantitative information regarding the effects of $\left[\mathrm{Ag}^{+}\right]$on the morphology of Ag@Fe NPs, a series of different spectra are also recorded as a function of $\left[\mathrm{Ag}^{+}\right]$from $2.0 \times 10^{-4} \mathrm{~mol} \mathrm{dm}^{-3}$ to $14.0 \times 10^{-4} \mathrm{~mol} \mathrm{dm}^{-3}$ in the absence and the presence of $[\mathrm{CTAB}]=10.0 \times 10^{-4}$ mol dm${ }^{-3}$ at a fixed $\left[\mathrm{Fe}^{3+}\right]=10.0 \times 10^{-4} \mathrm{~mol} \mathrm{dm}^{-3}$ [ascorbic acid $]=10.0 \times 10^{-4} \mathrm{~mol} \mathrm{dm}^{-3}$. Inspection of these data indicates that resulting pale yellow color shows a weak peak at $300 \mathrm{~nm}$ and a broad band absorption with band maximum at around $375 \mathrm{~nm}$ at $\left[\mathrm{Ag}^{+}\right]=10.0 \times 10^{-4} \mathrm{~mol} \mathrm{dm}^{-3}$ in the absence of CTAB (Fig. 7; black line), which is attributed to the characteristic surface resonance plasmon excitation of spherical FeNPs nanoparticles (Linnert et al. 1990). However, the spectra of the Ag@Fe NPs prepared at lower $\left[\mathrm{Ag}^{+}\right]$ from $2.0 \times 10^{-4} \mathrm{~mol} \mathrm{dm}^{-3}$ to $6.0 \times 10^{-4} \mathrm{~mol} \mathrm{dm}^{-3}$ show the appearance of different colors with two weak broad absorptions at 300 and $375 \mathrm{~nm}$ (Fig. 6; red and gray lines), indicating that large Ag@Fe NPs began to form, and also suggesting that during this stage, the resulting NCPs had a wide size distribution (Yu and Yam 2005; Zhang et al. 2004).

The extensive and red-shifting of the absorption band with $\left[\mathrm{Ag}^{+}\right]$indicate that $\left[\mathrm{Ag}^{+}\right]$has a significant effect on the morphology of $\mathrm{Ag} @ \mathrm{Fe} \mathrm{NPs}$, and finally, $\mathrm{Ag}^{+}$ions controlled the nucleation and growth processes and act as a 
shape-directing agent. According to Mie theory, depending upon the shape, both an anisotropic particles and single nanocrystals should exhibit a single- and multiple-surface plasmon bands (Kreibig and Vollmer 1995). The Ag nanoparticles observe plasmon absorption band in the visible region and no plasmon absorption bands are observed for the pure Fe nanoparticle in visible region. The possible excitations of higher multipode plasmon and quadrupole in larger metal particles are reasons behind the enhanced bands (Kamat et al. 1998). The bimetallic nature related to particles is conformed through a known physical individual components and its absorbance is compared with bimetallic Ag-Fe colloid of the same composition. The optical absorption spectra of $\mathrm{Ag}-\mathrm{Fe}$ alloy show different SRP peaks with the composition dependent $\lambda_{\max }$ at different positions. The plasmon band blue shifts with increasing $\left[\mathrm{Ag}^{+}\right]$(Fig. 7) and is similar to the observations of Link et al. (1999), Cheng et al. (2012). Nutt et al. (2005), and Bakshi (2009) for the $\mathrm{Ag}-\mathrm{Au}$ and $\mathrm{Pd}-\mathrm{Au}$ alloys, respectively. Thus, the TEM images fully support the UV-visible results and demonstrate that $\left[\mathrm{Ag}^{+}\right]$and reaction time are the important parameters, which clearly influence the morphology of resulting nanoparticles.

The metal polarizability is a surface-dependent property, playing a vital role in polarizability of metals, as a result shifts the resonance to optical frequencies (Ghosh et al. 2007; Ban et al. 2005). The plasmon absorption band of bulk $\mathrm{Ag}$ is around $420 \mathrm{~nm}$ and its values are dependent on reaction environment, particles size, shape, and dielectric properties. The red shift occurs in the SRP bands of Ag@Fe core/ shell NPs as compared to pure Ag nanoparticles at higher $\left[\mathrm{Ag}^{+}\right]$and $[\mathrm{CTAB}]$ attributes the formation of $\mathrm{Ag} @ \mathrm{Fe} \mathrm{NPs}$. The appearance of the strong surface plasmon absorption band at $450 \mathrm{~nm}$ may be because of formation of highly stable and non-oxidized Ag@Fe NPs (Fig. 7). The similar results have been observed for the other core-shell nanocomposites, such as Fe@Au nanoparticles (Chiang and Chen 2007) and Co@Ag nanoparticles (Garcia-Torres et al. 2010). Ghosh et al. have reported the similar interesting behavior in nanocomposites of $\mathrm{ReO}_{3} @ \mathrm{Ag}$ core-shell nanoparticles (Ghosh et al. 2007). Note that the obtained plasmon bands of the $\mathrm{Ag} @ \mathrm{Fe}$ core/shell NPs are much narrower as if compared with the reported ones of the core-shell nanoparticle coating with $\mathrm{Au}$ (Ban et al. 2005; Chiang and Chen 2007); in addition, the similar observations for the Co@ Ag core-shell nanoparticles were reported by Garcia-Torres et al. (2010). The said phenomenon can have the possibilities from the two predominant factors: (i) the agglomeration of nanoparticles result from the nearly uniform size and morphology is reason behind the narrow surface plasmon peaks in $\mathrm{Ag} @ \mathrm{Fe}$ core/shell nanoparticles. (ii) The sensitivity of silver (Ag) towards the surface plasmon resonance is more as compared with iron $(\mathrm{Fe})$.

\section{Mechanism of Ag@Fe formation}

Various species of ascorbic acid (ascorbic acid, ascorbate ion, protonated ascorbate radical, and ascorbate radical) coexist in a state of equilibrium in the presence two ionizable $\mathrm{pH}$ sensitive $-\mathrm{OH}$ groups with $\mathrm{pK}_{1}=4.2$ and $\mathrm{pK}_{2}=11.6$ (Creutz 1981). The well-versed fact related to the stability of metal nanoparticles, electron gaining, and/or losing ability of metal is dependent on $\mathrm{pH}$ of working reaction media. The different experimental conditions were taken in consideration while measuring the $\mathrm{pH}$ of working solutions both in the presence and in the absence of [CTAB]. Though increase in concentration of [ascorbic acid] as presented in Table 1 determines the nearly constant value of $\mathrm{pH}$ at ca. 4.2 , thus defines that the ascorbate is prime and productive species of ascorbic acid under our experimental conditions, i.e., $\mathrm{pH}=$ ca. 4.2. The reaction-time curve also indicates that absorbance remains constant after ca. 20 min, suggesting
Table 1 Effects of $\left[\mathrm{Fe}^{3+}\right] /\left[\mathrm{Ag}^{+}\right]$ and $\mathrm{CTAB}$ on the color, $\mathrm{pH}$, stability, reaction rates, and position of the SRP peak of $\mathrm{Ag} @ \mathrm{Fe}^{\mathrm{a}}$

\begin{tabular}{lllll}
\hline$\left[\mathrm{Fe}^{3+} / \mathrm{Ag}^{+}\right]$ & $\begin{array}{l}10^{4}[\mathrm{CTAB}] \\
(\mathrm{mol} \mathrm{dm})^{-3)}\end{array}$ & Appearance and stability & PH & $10^{3} k_{\mathrm{obs}}\left(\mathrm{s}^{-1}\right)$ \\
\hline $10: 10$ & 0.0 & Pale yellow; stable; weak shoulder & 5.6 & - \\
$10: 10$ & 10.0 & Brown; stable; $\lambda_{\max }=352,430 \mathrm{~nm}$ & 4.2 & 5.0 \\
$10: 1$ & 10.0 & pale yellow; stable; $\lambda_{\max }=352 \mathrm{~nm}$ & 4.2 & 4.2 \\
$10: 2$ & 10.0 & Brown; stable; $\lambda_{\max }=352,430 \mathrm{~nm}$ & 4.1 & 6.1 \\
$10: 4$ & 10.0 & Brown; stable; $\lambda_{\max }=352,430 \mathrm{~nm}$ & 4.1 & 7.4 \\
$10: 6$ & 10.0 & Brown; unstable; $\lambda_{\max }=352,430 \mathrm{~nm}$ & 4.2 & 6.2 \\
$10: 8$ & 10.0 & Brown; unstable; $\lambda_{\max }=352,430 \mathrm{~nm}$ & 4.2 & 5.5 \\
$10: 10$ & 10.0 & Brown; unstable; $\lambda_{\max }=352,430 \mathrm{~nm}$ & 4.2 & 5.0 \\
$10: 14$ & 10.0 & Brown; turbid; $\lambda_{\max }=352,430 \mathrm{~nm}$ & 4.2 & - \\
$10: 10$ & 2.0 & Yellow; stable; $\lambda_{\max }=352,430 \mathrm{~nm}$ & 4.3 & - \\
$10: 10$ & 6.0 & Yellow; stable; $\lambda_{\max }=352,430 \mathrm{~nm}$ & 4.2 & - \\
\hline
\end{tabular}

${ }^{\mathrm{a}}$ [ascorbic acid $]=10.0 \times 10^{-4} \mathrm{~mol} \mathrm{dm}^{-3}$ 
that the growth process has been completed within this period. The metals with high redox potential are generally reduced by weak reducing agents (Al-Thabaiti et al. 2008; Cho et al. 2009; Zhang et al. 2011). As a fact, Fe with low redox potential cannot reduce from $\mathrm{Fe}^{3+}$ ions to $\mathrm{Fe}^{0}$ in liquid phase in the presence of weak reducing agents (Liu et al. 2014). Situation is quite different in a reaction mixture containing $\mathrm{Ag}^{+}, \mathrm{Fe}^{3+}$ ions, and ascorbic acid (reduction potentials for the couples $\mathrm{Ag}^{+} / \mathrm{Ag}^{0}, \mathrm{Fe}^{3+} / \mathrm{Fe}^{0}$, and ascorbic acid/ dehydroascorbic acid are $+0.799,-0.04 \mathrm{~V}$, and $+0.40 \mathrm{~V}$ ).

The core/shell-type nanoparticles can be broadly defined as comprising a core (inner material) and a shell (outer layer material). In case of seed-growth method, one can create a core or shell of his own choice. In this method, core is reduced first and considered as a seed and the shell is later developed by the reduction of the shell component on the surface of the core (Guo et al. 2011; Lu et al. 2010). However, in case of seedless synthetic method, the reduction potential and the mixing time play an important role in the fabrication of the core/shell nanoparticles (Carroll et al. 2010a, b; Goia and Matijevic 1998). We reported the formation of the Ag@Fe core/shell nanomaterials by one-pot seedless synthetic method. In our reported method during the reduction process, Ag metal species with high reduction potential reduce first to form the core. On the other hand, Fe metal species reduce later because of low reduction potential as compared to Ag metal species (Deng et al. 2005; Wiley et al. 2005). The redox-transmetalation reactions are dominated by the standard reduction potentials of these two metal salts. The reduction rate of $\mathrm{Ag}^{+}$to $\mathrm{Ag}^{0}$ is faster than that of $\mathrm{Fe}^{3+}$ to $\mathrm{Fe}^{0}$, so $\mathrm{Ag}$ nanocores are initially formed. These Ag nanocores are reactive, serve as in situ seeds, and also provide catalytic surface for the growth of Fe nanoshells (Wiley et al. 2005). The other factor for the formation of $\mathrm{Ag}$ as a core and $\mathrm{Fe}$ as a shell could be the use of the surfactant (CTAB) that has the capacity to bond with the Ag metal because of its high redox potential that results in the stabilization of the core/shell arrangement (Goia and Matijevic 1998).

We were not able to observe any formation of AgNPs by reduction of $\mathrm{Ag}^{+}$ions with ascorbic acid at $\mathrm{pH} \leq 2.0$ within a short reaction time of $30 \mathrm{~min}$ (Chen and Liu 2011). There is a competition between metal ions, $\mathrm{Ag}^{+}$and $\mathrm{Fe}^{3+}$, to gain electrons from ascorbic acid. In the mixing solution, $\mathrm{Ag}^{+}$ions at high reducing potential as compared to $\mathrm{Fe}^{3+}$ ions and, therefore, were first reduced by ascorbic acid to generate AgNPs, and form a core. Subsequently, $\mathrm{Fe}^{3+}$ ions would be absorbed onto the of surface of AgNPs through van der Walls forces and reduced by under potential deposition, because iron is more reactive in the presence of less reactive metals and behave like active sites or seeds for further growth (Scheme 3). As a result, $\mathrm{Ag}_{\text {core }}-\mathrm{Fe}_{\text {shell }}$ NPs are formed:

$\mathrm{Fe}\left(\mathrm{H}_{2} \mathrm{O}\right)_{6}^{3+} \stackrel{\mathrm{K}_{\mathrm{h}}}{\rightleftharpoons}\left[\mathrm{Fe}(\mathrm{OH})\left(\mathrm{H}_{2} \mathrm{O}\right)_{5}\right]^{2+}+\mathrm{H}^{+}$

$n\left[\mathrm{Fe}(\mathrm{OH})\left(\mathrm{H}_{2} \mathrm{O}\right)_{5}\right]^{2+}+n \mathrm{Ag}^{0} \stackrel{\mathrm{K}_{\mathrm{ad}}}{\rightleftharpoons} n\left[\left(\mathrm{Fe}(\mathrm{OH})\left(\mathrm{H}_{2} \mathrm{O}\right)_{5}\right]^{2+}-\mathrm{Ag}^{0}\right)$

$n\left[\left(\mathrm{Fe}(\mathrm{OH})\left(\mathrm{H}_{2} \mathrm{O}\right)_{5}\right]^{2+}-\mathrm{Ag}^{0}\right) \stackrel{\text { Fast }}{\rightleftharpoons} \mathrm{Ag} @ \mathrm{Fe}$.

In Scheme 3, Eq. (9) represents the hydrolysis and/or anation of $\mathrm{Fe}^{3+}$ ions. The next step is the adsorption of $\mathrm{Fe}(\mathrm{OH})$ $\left(\mathrm{H}_{2} \mathrm{O}\right)_{5}^{2+}$ on the surface of AgNPs (Eq. 10). The reduction occurred on the surface of AgNPs through potential depositions with Ag@Fe core-shell nanoparticles synthesis (Eq. 11). The Ag:Fe ratio as governed for the controlled morphology of NPs is presented in Table 1 . These results are in a good approximation with theory and explanations already cited for co-reduction of two metal ions in an aqueous solution (Wang et al. 2016).

\section{Stability of Ag@Fe nanocomposites}

We observed the appearance of prefect transparent brown color sols at lower $\left[\mathrm{Ag}^{+}\right]=2.0 \times 10^{-4}$, which is stable at least for 1 month. On the other hand, the resulting sols became turbid at $\left[\mathrm{Ag}^{+}\right] \geq 6.0 \times 10^{-4}$ and $14.0 \times 10^{-4} \mathrm{~mol} \mathrm{dm}^{-3}$ after ca. $5 \mathrm{~min}$ of the reaction time. $\mathrm{At}^{+}=2.0 \times 10^{-4}$ mol dm $\mathrm{dm}^{-3}$, a weak SPR at $352 \mathrm{~nm}$ is visible along with the sharp SRP at $430 \mathrm{~nm}$, which be due to the simultaneously formation of Ag@Fe NPs. Appearance of turbidity is mainly related to the higher reactivity of FeNPs towards $\mathrm{Ag}^{+}$ions. To determine the reactivity of $\mathrm{Ag}^{+}$ions towards FeNPs and/or Ag@ $\mathrm{Fe} \mathrm{NPs,} \mathrm{an} \mathrm{aqueous} \mathrm{AgNO}_{3}$ solutions $\left(10.0 \times 10^{-4} \mathrm{~mol} \mathrm{dm}^{-3}\right)$ were added in the solutions of $\mathrm{Fe}\left(\mathrm{NO}_{3}\right)_{3}\left(10.0 \times 10^{-4} \mathrm{~mol} \mathrm{dm}^{-3}\right)$ and $\mathrm{Ag} @ \mathrm{Fe}$ nano-sols separately. However, there was no observance of any turbidity in a solution containing $\mathrm{AgNO}_{3}+\mathrm{Fe}\left(\mathrm{NO}_{3}\right)_{3}$ (reaction
Scheme 3 Mechanism to the formation of $\mathrm{Ag} @ \mathrm{Fe}$ bimetallic nanocomposites

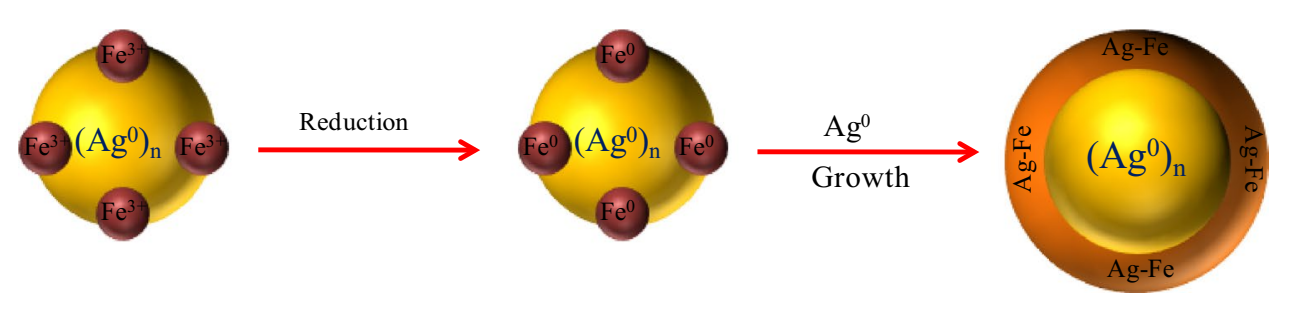


mixture remains colorless for a long period), whereas the perfect transparent dark-brown-colored Ag @ Fe sols became yellowish turbid, in turn reflects the presence of $\mathrm{Ag}^{+}$ions subjected to instability towards the Ag@Fe sols. On the basis of these, we may confidentially concluded that Ag@ Fe core-shell NPs are formed under our strategies. The following transmetallation reaction can be considered:

$\mathrm{Fe}^{0}+3 \mathrm{Ag}^{+} \rightarrow \mathrm{Fe}^{3+}+3 \mathrm{Ag}^{0}$

$\mathrm{Ag} @ \mathrm{Fe}+3 \mathrm{Ag}^{+} \rightarrow \mathrm{Ag} @ \mathrm{Fe}^{3+}+3 \mathrm{Ag}^{0}$.

Metallic Fe is a moderate reducing agent and susceptible to corrosion in aqueous solutions (Liu et al. 2014; Zhang 2003), which depends on the experimental conditions such as atmospheric oxygen and $\mathrm{pH}$. As these reactions have been carried out at room temperature, oxidation of $\mathrm{Fe}^{0}$ by dissolved $\mathrm{O}_{2}$ and water cannot be ruled out.
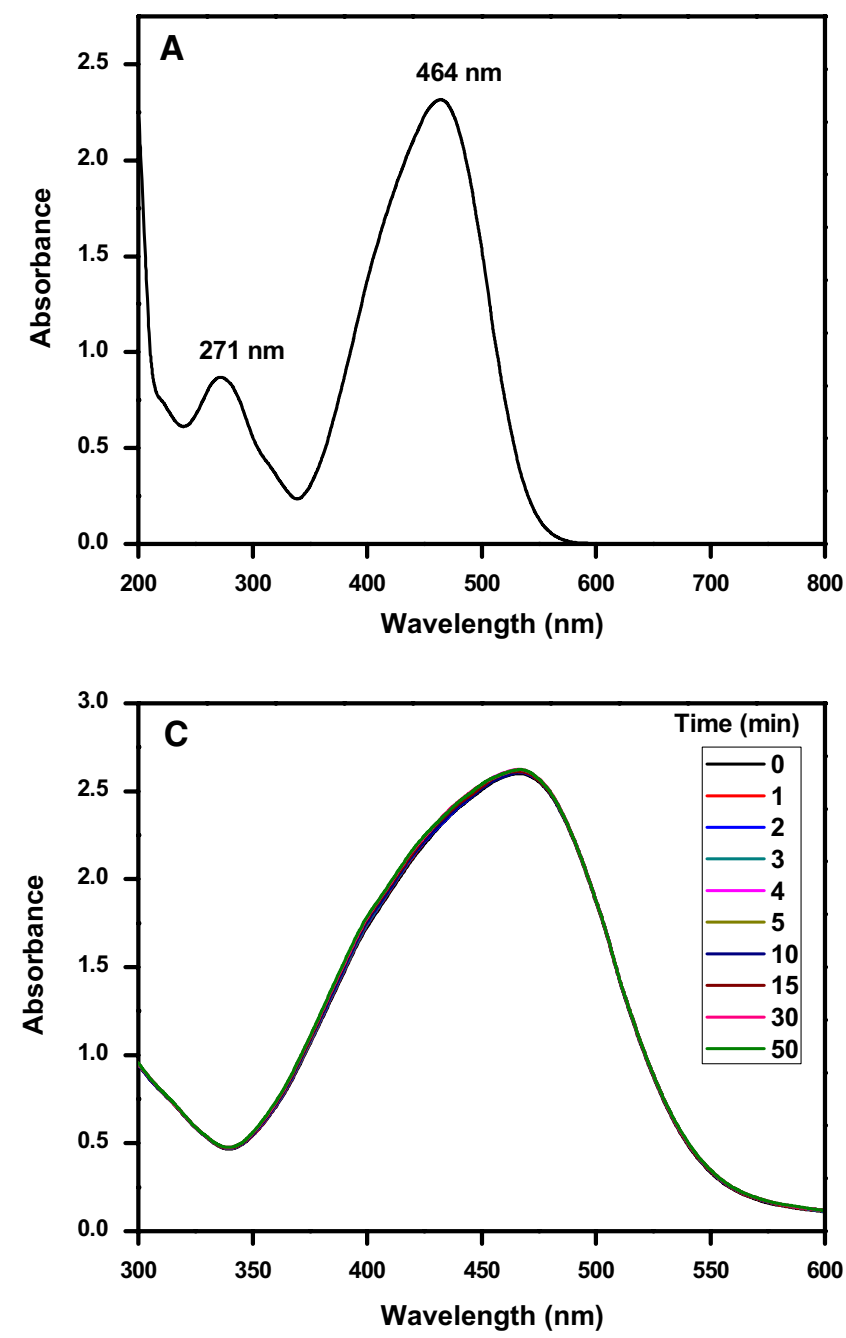

Fig. 8 a UV-visible spectra of methyl orange. b Timeresolved UV-visible spectra of [methyl orange] $=1.0 \times 10^{-4}$ mol dm$~_{-3}+\left[\mathrm{NaBH}_{4}\right]=1.0 \times 10^{-3} \mathrm{~mol} \mathrm{dm}^{-3}$. c UV visible spectra

\section{Catalytic reduction of methyl orange}

To determine the catalytic activity of Ag@Fe NPs towards methyl orange, UV-visible spectra of reaction mixture containing methyl orange $+\mathrm{NaBH}_{4}$, methyl orange $+\mathrm{Ag} @$ $\mathrm{Fe} \mathrm{NPs}$, and methyl orange $+\mathrm{NaBH}_{4}+\mathrm{Ag} @ \mathrm{Fe} \mathrm{NPs}$ were recorded at different time intervals. It is well known that the spectrum of methyl orange shows two peaks at $464 \mathrm{~nm}$ for $-\mathrm{N}=\mathrm{N}-$, azo bonding and $271 \mathrm{~nm}$ to the benzene ring of methyl orange (Fig. 8a). The wavelength $464 \mathrm{~nm}$ was chosen for the determination of catalytic activity. In the absence of $\mathrm{Ag} @ \mathrm{Fe} \mathrm{NPs}, \mathrm{NaBH}_{4}$ has no effect on the position of methyl orange peak at $464 \mathrm{~nm}$ and absorbance remains constant (Fig. 8b) (Mondal et al. 2015). The spectra of Ag@ $\mathrm{Fe}+$ methyl orange solution also show no peak at $430 \mathrm{~nm}$ for Ag@Fe, which might be due to the complexation formation between the Ag@Fe NPs and methyl orange. The main
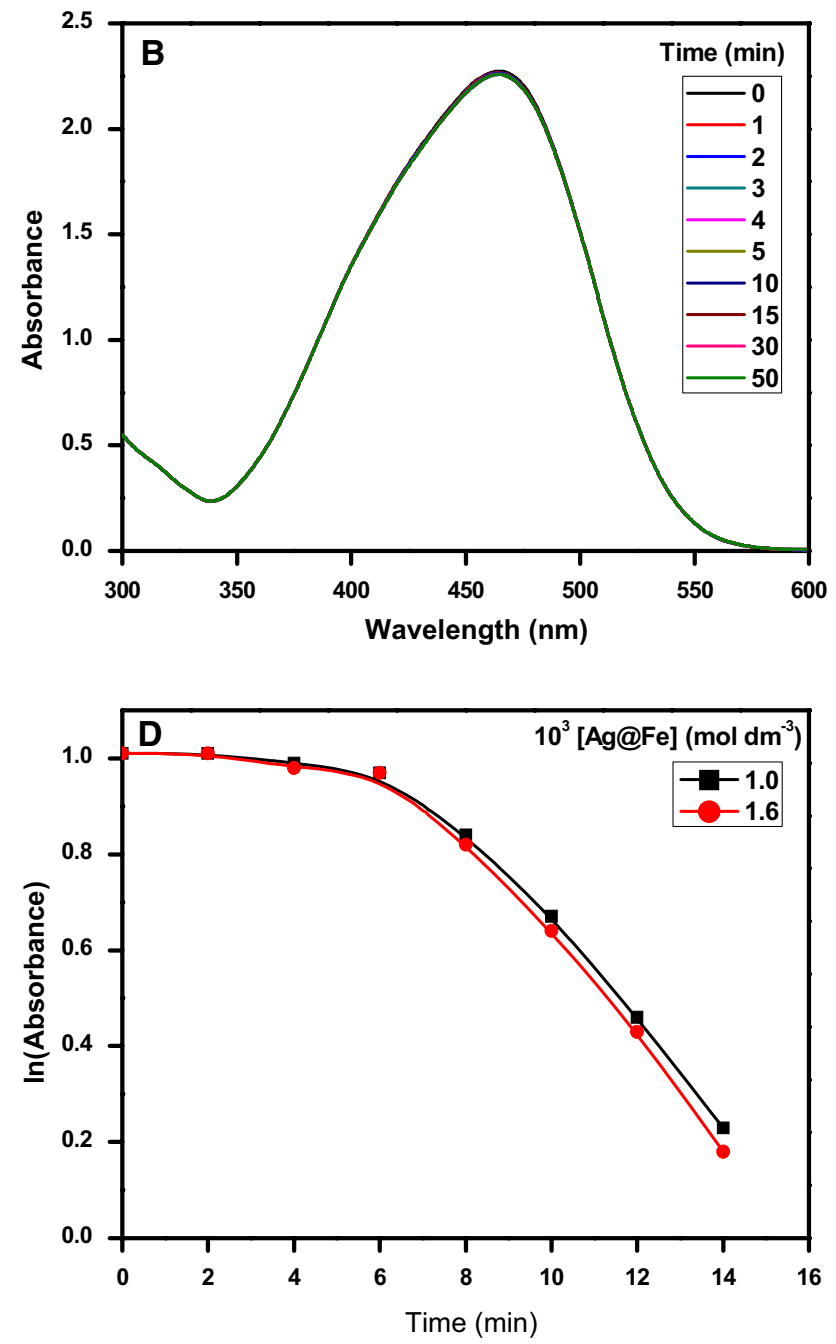

of $[\mathrm{Ag} @ \mathrm{Fe}]=1.6 \times 10^{-3} \mathrm{~mol} \mathrm{dm}{ }^{-3}+[$ methyl orange $]=1.0 \times 10^{-4}$ mol dm${ }^{-3}$. d Pseudo-first-order plot for the methyl orange reduction 
focus is to study the effect on SPR band of methyl orange at $464 \mathrm{~nm}$ as it is responsible for the orange color of the MO dye. It was also observed that in the absence of $\mathrm{NaBH}_{4}$, the methyl orange peak at $464 \mathrm{~nm}$ neither changes its position nor decreases in intensity with Ag@Fe NPs (Fig. 8c). Thus, we may state confidently that neither Ag@Fe NPs nor $\mathrm{NaBH}_{4}$ is in a position to reduce the methyl orange. Interestingly, the methyl orange absorption peak decreases were very fast as soon as $\mathrm{Ag} @ \mathrm{Fe}$ added into the mixture of methyl orange $+\mathrm{NaBH}_{4}$, indicating the catalytic role of $\mathrm{Ag} @ \mathrm{Fe}$ (Fig. 8d). Surprisingly, as the reduction proceeds, the disappearance and appearance of the peak at 464 and $430 \mathrm{~nm}$, respectively, were observed during the course of the reaction simultaneously. Initially, we did not observe the peak of Ag@Fe at $430 \mathrm{~nm}$, which remained masked within the peak of methyl orange (Fig. 9).

The modified Langmuir-Hishelwood pseudo-first-order kinetic model has been used to explain the catalytic activity of Ag@Fe NPs (Pouretedal and Keshavarz 2010):

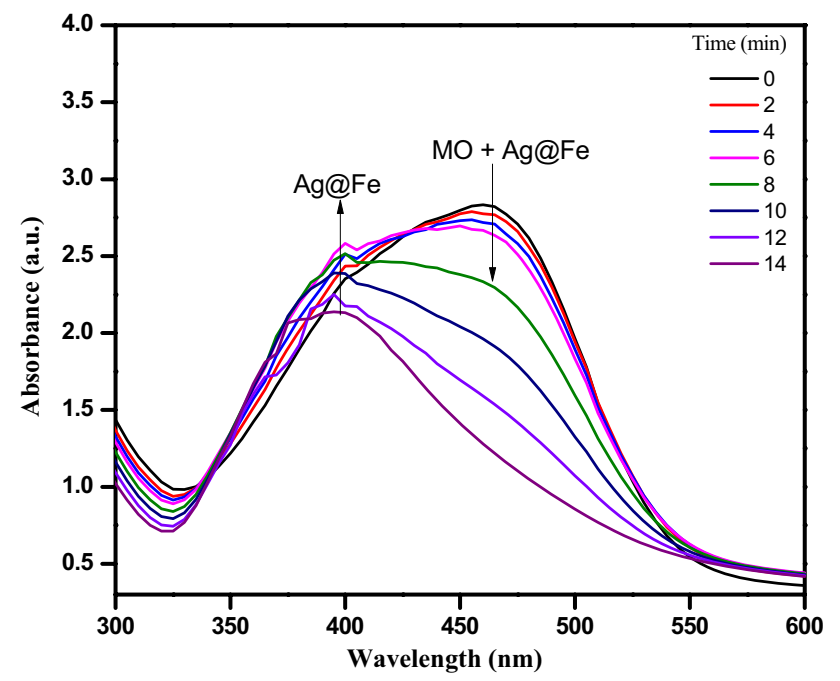

Fig. 9 Reduction of methyl orange $=1.0 \times 10^{-4} \mathrm{~mol} \mathrm{dm}^{3}$ by $\mathrm{Ag} @$ $\mathrm{Fe}=1.6 \times 10^{-3} \mathrm{~mol} \mathrm{dm}^{-3}$ in the presence of $\left[\mathrm{NaBH}_{4}\right]=1.0 \times 10^{-3}$ mol dm${ }^{-3}$ as a function of time at room temperature $\ln \left(C_{0} / C_{\mathrm{t}}\right)=k K_{\mathrm{ad}} t=k t$,

where $k=$ apparent first-order rate constant $\left(\mathrm{s}^{-1}\right)$, and $K_{\text {ad }}=$ absorption coefficient of the methyl orange onto the catalyst particle.

Interestingly, degradation process is sigmoid in nature (induction period followed by an autoacceleration). It was observed that the absorbance remains constant (induction period) up to ca. $6 \mathrm{~min}$ of the reaction time, which might be ascribed to the time taken for the activation of catalyst surface and/or transfer of electrons from $\mathrm{NaBH}_{4}$ to methyl orange through Ag@Fe. The apparent pseudo-first-order rate constant is found to vary linearly with $\left[\mathrm{NaBH}_{4}\right]$. Equation (15) was used for the estimation of turnover frequency (number of moles of methyl orange reduced per mole of catalyst per time and is equal to $\mathrm{k}$, apparent rate constant, at the saturation limit for the first-order reactions (Holden et al. 2014; Kozuch and Martin 2012; Umpierre et al. 2011):

$\mathrm{TOF}=-\mathrm{d} N / \mathrm{d} t=k[C] / C^{0}$.

The values of apparent first-order rate constant and TOF are summarized in Table 2, which clearly shows that the rate constant values are in the same magnitude with the results of other investigators (Gupta et al. 2011). Equation (2) was used for the calculation of percentage reduction of methyl orange. Reaction-time profiles suggested that the $60 \%$ $\mathrm{MO}$ has been reduced with in $14 \mathrm{~min}$ of the reaction time (Fig. 10a). The effect of temperature (from 298 to -318 K) was also studied at fixed concentrations of all reactants. The Arrhenius plot of $\log \left(k_{\mathrm{obs}}\right)$ versus $1 / T$ was found to be linear. The value of activation energy, $E_{\mathrm{a}}=58.2 \mathrm{~kJ} \mathrm{~mol}^{-1}$, was calculated from the slope (Fig. 10b). To determine the reusability capacities of Ag@Fe, the used NCPs are separated from the reaction system using a magnetic bar. The solutions were decanted and magnetic bar containing the NCPs was dispersed in the double-distilled water. The resulting black particle dispersion solution was re-used for the reduction of MO under similar [MO], $\left[\mathrm{NaBH}_{4}\right]$, and temperature. These experiments suggest that the reusability of the NCPs catalyst exhibits a similar catalytic performance for running 10
Table 2 Apparent first-order rate constants $\left(k_{\text {app }}\right)$, turnover frequency (TOF), and $E_{\mathrm{a}}$ for the catalytic activity of $\mathrm{Ag} @ \mathrm{Fe}$ as a catalyst

\begin{tabular}{lllll}
\hline Reaction system & $k_{\text {app }}\left(\mathrm{s}^{-1}\right)$ & $\mathrm{TOF}\left(\mathrm{s}^{-1}\right)$ & $E_{\mathrm{a}} \mathrm{kJ} \mathrm{mol}^{-1}$ & Refs. \\
\hline AgNPs + $\mathrm{MO}+\mathrm{NaBH}_{4}(0.0016 \mathrm{M})$ & $1.6 \times 10^{-3}$ & $1.1 \times 10^{-3}$ & 58.2 & [This work] $^{\mathrm{a}}$ \\
AgNPs + $\mathrm{MO}+\mathrm{NaBH}_{4}(0.0024 \mathrm{M})$ & $1.8 \times 10^{-3}$ & & & [This work] $^{\mathrm{a}}$ \\
$\mathrm{AgNPs}+\mathrm{MO}+\mathrm{NaBH}_{4}(0.0031 \mathrm{M})$ & $2.0 \times 10^{-3}$ & & [This work] $^{\mathrm{a}}$ \\
$\mathrm{AgNPs}+\mathrm{MO}+\mathrm{NaBH}_{4}(0.004 \mathrm{M})$ & $2.5 \times 10^{-3}$ & & [This work] $^{\mathrm{a}}$ \\
$\mathrm{AgNPs}+\mathrm{MO}$ & $9.7 \times 10^{-3}$ & & & {$[78]$} \\
$\mathrm{AgNPs}+\mathrm{MO}$ & $3.2 \times 10^{-3}$ & & & {$[79]$} \\
$\mathrm{Ag} @ \mathrm{Fe}_{2} \mathrm{O}_{3}+4-\mathrm{NP}$ & $1.5 \times 10^{-2}$ & 0.22 & 45 & {$[73]$} \\
$\mathrm{Ag} @ \mathrm{Au}+4-\mathrm{NP}$ & $5.7 \times 10^{-3}$ & $3.7 \times 10^{-3}$ & 63 & {$[75]$} \\
\hline
\end{tabular}

${ }^{\mathrm{a}}$ Reaction conditions: $[\mathrm{Ag} @ \mathrm{Fe}]=1.6 \times 10^{-3} \mathrm{~mol} \mathrm{dm}{ }^{-3},[\mathrm{MO}]=1.0 \times 10^{-4} \mathrm{~mol} \mathrm{dm}^{3}$ 

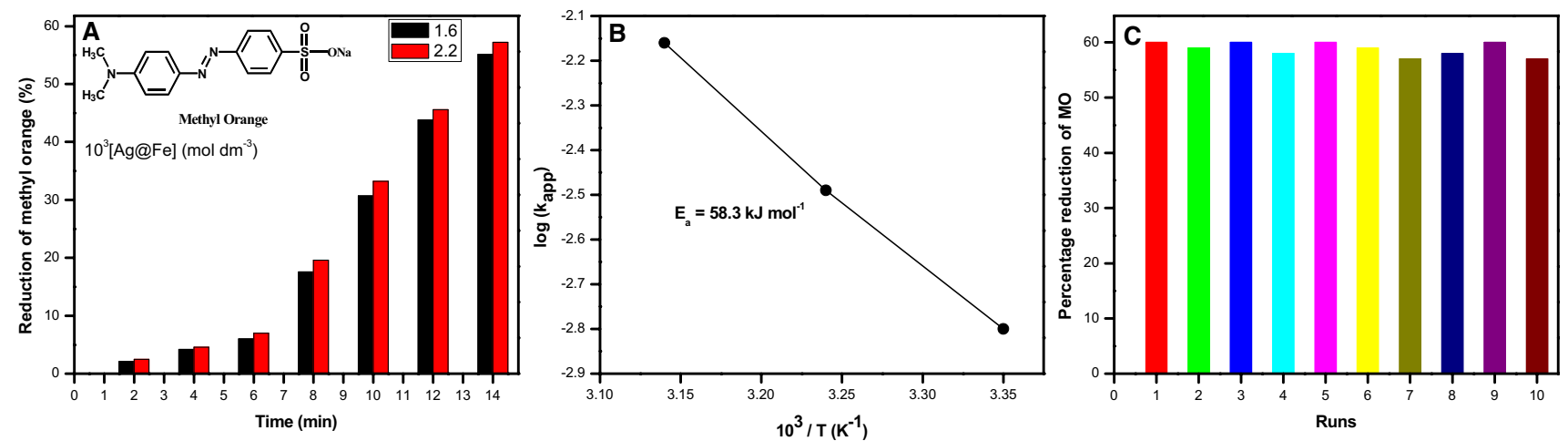

Fig. 10 a Variation of methyl orange \% degradation $\left(=1.0 \times 10^{-4} \mathrm{~mol} \mathrm{dm}^{-3}\right)$ with time as a function of catalyst dose. b Arrhenius plot for the reduction of methyl orange. $\mathbf{c}$ Recyclability of the Ag@Fe core/shell nanocomposite for MO dye degradation

cycles of the reaction (Fig. 10c), which might be due to the excellent stability and a long life of the resulting Ag@Fe NPs, which are as per results of Li et al. (2016) and Shin et al. (2009) to the reduction of 4-NP by CoNPs and silverdoped magnetic NPs, respectively. The above basic results trigger the following mechanism of catalytic degradation of methyl orange as proposed as:

In Scheme 4, redox reaction proceeds through the intermediate complex formation between MO, Ag@Fe NPs and $\mathrm{BH}_{4}^{-}$. In the next step, complex undergoes to the four-electron transfer (rate-determining step) from the $\mathrm{BH}_{4}{ }^{-}$(donor) to $-\mathrm{N}=\mathrm{N}-$ linkage of $\mathrm{MO}$ (acceptor) via $\mathrm{Ag} @ \mathrm{Fe}$ NPs (electron transfer mediator).

The dye degradation of methyl orange by $\mathrm{Ag} @ \mathrm{Fe}$ core/shell nanoparticles is compared with the MO dye degradation obtained so far using other nanocatalysts. The catalytic effect of monometallic Ag and Fe nanoparticles is given in Table 3 (Sharma et al. 2014). Amount of catalyst plays an important role in dye degradation reaction rate, because the number of active sites on the surface of the catalyst increases with an increase in the catalyst dose. Consequently causing an increase in the number of $\mathrm{OH}$ radicals which can take part in actual discoloration of MO dye solution. At constant MO dye concentration $\left(1.0 \times 10^{-4} \mathrm{~mol} \mathrm{dm}^{-3}\right)$, two $\mathrm{Ag} @ \mathrm{Fe}$ nanocatalyst concentrations $\left(1.6 \times 10^{-4}\right.$ and $\left.2.2 \times 10^{-4} \mathrm{~mol} \mathrm{dm}^{-3}\right)$ were used to investigate the effect of catalyst concentration on MO dye degradation. It was clearly observed that dye degradation reaction increases with an increase in the Ag@Fe nanocatalyst dose (Fig. 10a). The active surface sites for the reaction

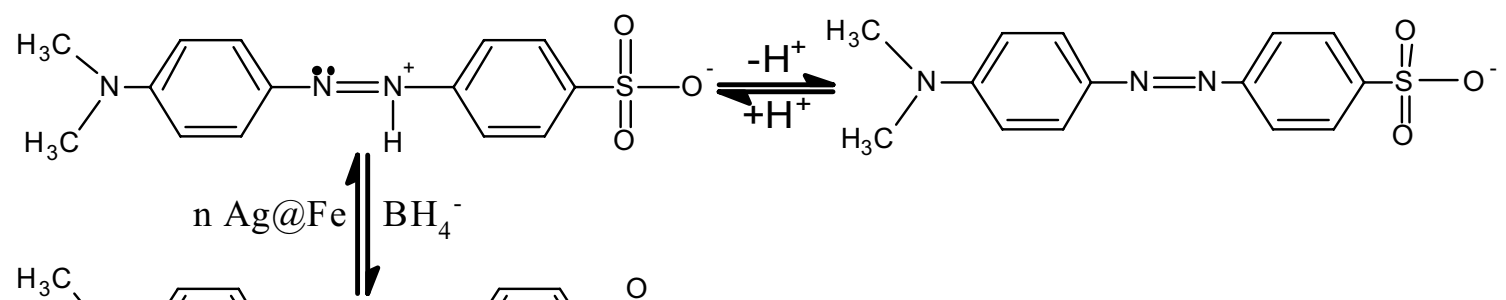<smiles>CN(C)c1ccc(N(C(=O)[O-])c2ccc(S(=O)(=O)[O-])cc2)cc1</smiles>

(complex: MO-Ag@Fe-BH ${ }_{4}$ )

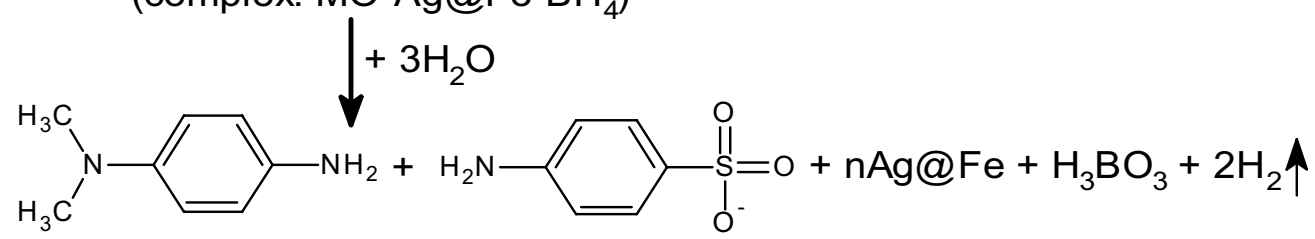

Scheme 4 Mechanism for the degradation of methyl orange by $\mathrm{NaBH}_{4}$ in the presence of $\mathrm{Ag} @ \mathrm{Fe}$ as a catalyst 
Table 3 Comparison of synthesized Ag@Fe core/shell with other catalysts used for the degradation of methyl orange (MO)

\begin{tabular}{|c|c|c|c|c|c|}
\hline Nanocatalyst & {$[\mathrm{MO}]$} & Condition & Time $(\min )$ & $\begin{array}{l}\text { Degrada- } \\
\text { tion }(\%)\end{array}$ & References \\
\hline Ag@Fe Core/Shell NPs & $1.0 \times 10^{-4} \mathrm{~mol} \mathrm{dm}^{-3}$ & $\mathrm{NaBH}_{4}$ & 14 & 55 & Present work \\
\hline Ag NPs & $0.01 \times 10^{-2} \mathrm{M}$ & $\mathrm{NaBH}_{4}$ & 11 & 98 & Joseph and Mathew (2015) \\
\hline $\mathrm{SiO}_{2}-\mathrm{Co}$ Core-Shell NPs & $0.076 \mathrm{mM}$ & $\mathrm{NaBH}_{4}$ & 1 & 96 & Zhang et al. (2016) \\
\hline Ag NPs & $1 \times 10^{-3} \mathrm{M}$ & $\mathrm{NaBH}_{4}$ & 6 & 95 & Vidhu and Philip (2014) \\
\hline Au NPs & $1 \times 10^{-4} \mathrm{M}$ & $\mathrm{NaBH}_{4}$ & 8 & 99 & Umamaheswari et al. (2018) \\
\hline $\mathrm{Fe}_{3} \mathrm{O}_{4} @ \mathrm{NH}_{2}{ }^{-}$mesoporous silica@PPy/Pd & $50 \mathrm{mg} \mathrm{L}^{-} 1$ & $\mathrm{NaBH}_{4}$ & 10 & 99 & Snoussi et al. (2018) \\
\hline $\mathrm{Au}-\mathrm{Ag}$ bimetallic NPs & $5 \times 10^{-3} \mathrm{M}$ & $\mathrm{NaBH}_{4}$ & 4 & 91 & Kumari et al. (2015) \\
\hline $\mathrm{Bi}_{2} \mathrm{O}_{3} / \mathrm{TiO}_{2}$ nanocomposites & $5 \mathrm{ppm}$ & UV light & 240 & 99 & Malligavathy et al. (2017) \\
\hline $\begin{array}{l}\mathrm{Fe}_{2} \mathrm{O}_{3}-\mathrm{Fe}_{3} \mathrm{O}_{4} \mathrm{NPs} \\
\mathrm{Fe}_{2} \mathrm{O}_{3}-\mathrm{Fe}_{3} \mathrm{O}_{4}-\text { montmorillonite nanocomposites }\end{array}$ & $20 \mathrm{mg} \mathrm{L}^{-} 1$ & Visible light & 290 & 99 & Wang et al. (2017) \\
\hline $\mathrm{Ag}-\mathrm{Ni}$ NPs & $2.0 \times 10^{-4} \mathrm{~mol} \mathrm{dm}^{-3}$ & UV light & 60 & 99 & Alruqi et al. (2018) \\
\hline $\mathrm{ZnFe}_{2-\mathrm{x}} \mathrm{La}_{\mathrm{x}} \mathrm{O}_{4} \mathrm{NPs}$ & $3.30 \times 10^{-3} \mathrm{M}$ & UV light & 80 & 85 & Talebi et al. (2016) \\
\hline$\alpha-\mathrm{Fe}_{2} \mathrm{O}_{3}$ NPs & $40 \mathrm{ppm}$ & UV light & 210 & 80 & Talebi et al. (2016) \\
\hline CoNPs & $2 \times 10^{-6} \mathrm{M}$ & $\mathrm{NaBH}_{4}$ & 16 & NA & Mondal et al. (2015) \\
\hline
\end{tabular}

to proceed are blocked with the turbidity at certain catalyst amounts, which aided to start the decreased percentage of degradation.

The economically feasible product and process of any catalyst is of applying importance and relays on its sustainability, stability, and recovery. To evaluate the reusability and catalytic stability of the Ag@Fe nanocomposite catalyst, recycling experiments were performed. To ensure that all the nanoparticles have been settled, nanoparticles were weighted after drying and it was found that the amount of recovered nanoparticles is the same as the initial amount. It was separated from the reaction mixture after its first use in the degradation of MO. The recovered catalyst was found to be re-usable for ten runs without significant loss in activity. Noticeably, the investigated Ag@Fe NPs exhibited high degradation activity, without any significant loss in its catalytic performance even after ten consecutive cycles (Fig. 10c). This result makes nanocomposite more cost-effective as well as eco-friendly for industrial applications.

\section{Conclusions}

A competitive co-reduction method is used to synthesize $\mathrm{Ag} @$ Fe bimetallic NCPs using $\mathrm{Ag}^{+}+\mathrm{Fe}^{3+}+\mathrm{CTAB}+$ ascorbic acid at room temperature. The end product of the reaction yields AgNPs. The reduction of $\mathrm{Fe}^{3+}$ ions on AgNPs surface turns into formation of core-shell Ag@Fe NPs simultaneously. The results have been explained on the basis of the reduction potentials of the metal precursor, TEM, FTIR XRD, and EDX. The stability of Ag@Fe NPs depends on $\left[\mathrm{Ag}^{+}\right]$. The peak intensity and the morphology of the UV-visible spectra have been thoroughly changed at higher $\left[\mathrm{Ag}^{+}\right]$. Reactivity of $\mathrm{Fe}^{0}$ is higher with $\mathrm{Ag}^{+}$, which oxidizes the shell of Ag@Fe NPs. The possibility to the oxidative corrosion triggered by dissolved oxygen can not be ruler out. The pre- and post-micellar catalytic effect was also investigated to observe the effect of [CTAB] on Ag@ Fe NPs' formation and morphology. The catalytic activity of as-prepared Ag@Fe NPs has been investigated in the degradation and/or reduction of methyl orange in the presence of $\mathrm{NaBH}_{4}$ as a source of hydrogen. The activation energy for the catalytic reduction is also estimated to be $58.2 \mathrm{~kJ} \mathrm{~mol}^{-1}$. Our Ag@Fe NPs is cost-effective, re-usable catalyst for the removal of toxic materials from the industrial wastes and other catalytic applications.

\section{References}

Alruqi SS, Al-Thabaiti SA, Malik MA, Khan Z (2018) Role of surfactants: one step facile synthesis of hetero structured $\mathrm{Ag}-\mathrm{Ni}$ alloy by seed less approach. Colloids Surf A 540:36-47

Al-Thabaiti SA, Al-Nowaiser FM, Obaid AY, Al-Youbi AO, Khan Z (2008) Formation and characterization of surfactant stabilized silver nanoparticles: a kinetic study. Colloid Surfaces B: Biointerfaces 67:230-237

Al-Thabaiti SA, Obaid AY, Khan Z, Bashir O, Hussain S (2015) Cu nanoparticles: synthesis, crystallographic characterization, and stability. Colloid Polym Sci 293:2543-2554

Al-Thabaiti SA, Aazam ES, Khan Z, Bashi O (2016) Aggregation of Congo red with surfactants and Ag-nanoparticles in an aqueous solution. Spectrochim Acta Part A Mol Biomol Spectrosc 156:28-35

Al-Thabaiti NS, Malik MA, Khan Z (2017) Protein interactions with silver nanoparticles: green synthesis, and biophysical approach. Int J Biol Macromol 95:421-428

Bakshi MS (2009) 1D flower-like morphologies of palladium nanoparticles using strongly hydrophobic surfactants. J Phys Chem C 113:10921-10928 
Ban ZH, Barnakov YA, Li F, Golub VO, O’Conner CJ (2005) J Mater Chem 15:4660-4662

Carroll KJ, Hudgins DM, Spurgeon S, Kemner KM, Mishra B, Boyanov MI, Brown LW, Taheri ML, Carpenter EE (2010a) One-pot aqueous synthesis of $\mathrm{Fe}$ and $\mathrm{Ag}$ core/shell nanoparticles. Chem Mater 22:6291-6296

Carroll KJ, Hudgins DM, Spurgeon S, Kemner KM, Mishra B, Boyanov MI, Brown LW III, Taheri ML, Carpenter EE (2010b) Onepot aqueous synthesis of $\mathrm{Fe}$ and $\mathrm{Ag}$ core/shell nanoparticles. Chem Mater 22:6291-6296

Chen HM, Liu RS (2011) Architecture of metallic nanostructures: synthesis strategy and specific applications. J Phys Chem C 115:3513-3527

Chen ZP, Zhang Y, Zhang S, Xia JG, Liu JW, Xu K, Gu N (2008) Preparation and characterization of water-soluble monodisperse magnetic iron oxide nanoparticles via surface double-exchange with DMSA. Colloid Surface A Physicochem Eng Aspects 316:210-216

Cheng L-C, Huang J-H, Chen HM, Lai T-C, Yang K-Y, Liu R-S, Hsiao M, Chen C-H, Here L-J, Tsai DP (2012) Seedless, silver-induced synthesis of star-shaped gold/silver bimetallic nanoparticles as high efficiency photothermal therapy reagent. J Mater Chem 22:2244-2253

Chiang IC, Chen DH (2007) Synthesis of monodisperse FeAu nanoparticles with tunable magnetic and optical properties. Adv Funct Mater 17:1311-1316

Cho EC, Cobley CM, Rycenga M, Xia Y (2009) Fine tuning the optical properties of $\mathrm{Au}-\mathrm{Ag}$ nanocages by selectively etching Ag with oxygen and a water-soluble thiol. J Mater Chem 19:6317-6320

Colvin VL, Goldstein AN, Alivisatos AP (1992) Semiconductor nanocrystals covalently bound to metal surfaces with self-assembled monolayers. J Am Chem Soc 114:5221-5230

Creutz C (1981) Complexities of ascorbate as a reducing agent. Inorg Chem 20:4449-4452

Crow D (1988) Principles and applications of electrochemistry. Chapman and Hall, London

Deng H, Li X, Peng Q, Wang X, Chen J, Li Y (2005) Monodisperse magnetic single-crystal ferrite microspheres. Angew Chem Int Ed 44:2782-2785

Ferrando R, Jellinek J, Johnston RL (2008) Nanoalloys: from theory to applications of alloy clusters and nanoparticles. Chem Rev 108:845-910

Garcia-Torres J, Vallés E, Gómez E (2010) Synthesis and characterization of Co@Ag core-shell nanoparticles. J Nanopart Res 12:2189-2199

Ghauch A, Tuqan A (2009) Reductive destruction and decontamination of aqueous solutions of chlorinated antimicrobial agent using bimetallic systems. J Hazard Mater 164:665-674

Ghosh S, Biswas K, Rao CNR (2007) Core-shell nanoparticles based on an oxide metal: $\mathrm{ReO}_{3} @ \mathrm{Au}(\mathrm{Ag})$ and $\mathrm{ReO}_{3} @ \mathrm{SiO}_{2}\left(\mathrm{TiO}_{2}\right)$. J Mater Chem 17:2412-2417

Goia DV, Matijevic E (1998) Preparation of monodispersed metal particles. New J Chem 22:1203-1215

Guo L, Huang Q, X-y L, Yang S (2001) Iron nanoparticles: synthesis and applications in surface enhanced Raman scattering and electrocatalysis. Phys Chem Chem Phys 3:1661-1665

Guo H, Chen Y, Chen X, Wen R, Yue G-H, Peng D-L (2011) Facile synthesis of near-monodisperse Ag@ Ni core-shell nanoparticles and their application for catalytic generation of hydrogen. Nanotechnology 22:195604 (8 pp)

Gupta N, Singh HP, Sharma RK (2011) Metal nanoparticles with high catalytic activity in degradation of methyl orange: an electron relay effect. J Mol Catal A Chem 335:248-252

Harrold SP (1960) Purification of sodium dodecyl sulfate. J Colloid Sci 15:280-282
Henglein A (1993) Physicochemical properties of small metal particles in solution: "microelectrode" reactions, chemisorption, composite metal particles, and the atom-to-metal transition. J Phys Chem 97:5457-5471

Hoag GE, Collins JB, Holcomb JL, Hoag JR, Nadagouda MN, Varma RS (2009) Degradation of bromothymol blue by 'greener' nanoscale zero-valent iron synthesized using tea polyphenols. J Mater Chem 19:8671-8677

Holden MS, Nick KE, Hall M, Milligan JR, Chen Q, Perry CC (2014) Synthesis and catalytic activity of pluronic stabilized silver-gold bimetallic nanoparticles. RSC Adv 4:52279-52288

Huber DL (2005) Synthesis, properties, and applications of iron nanoparticles. Small 1:482-501

Hyeon T, Lee SS, Park J, Chung Y, Na HB (2001) Synthesis of highly crystalline and monodisperse maghemite nanocrystallites without a size-selection process. J Am Chem Soc 123:12798-12801

Joseph S, Mathew B (2015) Microwave-assisted green synthesis of silver nanoparticles and the study on catalytic activity in the degradation of dyes. J. Mol Liquids 204:184-191

Kamat PV, Flumiani M, Hartland GV (1998) Picosecond dynamics of silver nanoclusters. Photoejection of electrons and fragmentation. J Phys Chem B 102:3123-3128

Khan Z, Obaid AY (2016) Seedless, copper-induced synthesis of stable $\mathrm{Ag} / \mathrm{Cu}$ bimetallic nanoparticles and their optical properties. RSC Adv 6:29116-29126

Khan Z, Al-Thabaiti SA, Hussain S (2016) Nanoscale water soluble self-assembled zero-valent iron: role of stabilizers in their morphology. RSC Adv 6:7267-7278

Koya PA, Wagay TA, Ismail K (2015) Conductometric studies on micellization of cationic surfactants in the presence of glycine. $\mathrm{J}$ Solut Chem 44:100-111

Kozuch S, Martin JML (2012) “Turning over” Definitions in catalytic cycles. ACS Catal 2:2787-2794

Kreibig U, Vollmer M (1995) Optical properties of metal clusters. Springer, Berlin

Kumari MM, John J, Philip D (2015) Green synthesis and applications of $\mathrm{Au}-\mathrm{Ag}$ bimetallic nanoparticles. Spectrochim Acta Part A Mol Biomol Spectrosc 137:185-192

Lai D, Liu T, Jiang G, Chen W (2013) Synthesis of highly stable dispersions of copper nanoparticles using sodium hypophosphite. J Appl Polym Sci 128:1443-1449

Laurent S, Forge D, Port M, Roch A, Robic C, Elst LV, Muller RN (2008) Magnetic iron oxide nanoparticles: synthesis, stabilization, vectorization, physicochemical characterizations, and biological applications. Chem Rev 108:2064-2110

Li X, Zeng C, Jiang J, Ai L (2016) Magnetic cobalt nanoparticles embedded in hierarchically porous nitrogen-doped carbon frameworks for highly efficient and well-recyclable catalysis. J Mater Chem A 4:7476-7482

Lin J, Zhou W, Kumbhar A, Wiemann J, Fang J, Carpenter EE, O'Connor CJ (2001) Gold-coated iron (Fe@ Au) nanoparticles: synthesis, characterization, and magnetic field-induced selfassembly. J Solid State Chem 159:26-31

Lina P-C, Lina S, Wanga PC, Sridhar R (2014) Techniques for physicochemical characterization of nanomaterials. Biotechnol Adv 32:711-726

Link S, Wang ZL, Al-Sayed MA (1999) Alloy formation of gold-silver nanoparticles and the dependence of the plasmon absorption on their composition. J Phys Chem B 103:3529-3533

Linnert T, Mulvaney P, Hanglein A, Weller H (1990) Long-lived nonmetallic silver clusters in aqueous solution: preparation and photolysis. J Am Chem Soc 112:4657-4664

Liu W-J, Qian T-T, Jiang H (2014) Bimetallic Fe nanoparticles: recent advances in synthesis and application in catalytic elimination of environmental pollutants. Chem Eng J 236:448-463

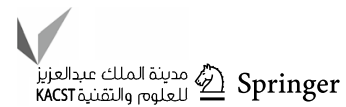


Lu A-H, Salabas EL, Schuth F (2007) Magnetic nanoparticles: synthesis, protection, functionalization, and application. Angew Chem Int Ed 46:1222-1244

Lu L, Zhang W, Wang D, Xu X, Miao J, Jiang Y (2010) Fe@ Ag core-shell nanoparticles with both sensitive plasmonic properties and tunable magnetism. Mater Lett 64:1732-1734

Luo S, Yang S, Wang X, Sun C (2010) Reductive degradation of tetrabromobisphenol A over iron-silver bimetallic nanoparticles under ultrasound radiation. Chemosphere 79:672-678

Luo S, Yang S, Sun C, Gu J-D (2012) Improved debromination of polybrominated diphenyl ethers by bimetallic iron-silver nanoparticles coupled with microwave energy. Sci Total Environment 429:300-308

Malligavathy M, Iyyapushpam S, Nishanthi ST, Padiyan DP (2017) Remarkable catalytic activity of $\mathrm{Bi}_{2} \mathrm{O}_{3} / \mathrm{TiO}_{2}$ nanocomposites prepared by hydrothermal method for the degradation of methyl orange. J Nanopart Res 19:144

Mondal A, Adhikary B, Mukherjee D (2015) Room-temperature synthesis of air stable cobalt nanoparticles and their use as catalyst for methyl orange dye degradation. Colloid Surface A Physicochem Eng Aspects 482:248-257

Mornet S, Vasseur S, Grasset F, Duguet E (2004) Magnetic nanoparticle design for medical diagnosis and therapy. J Mater Chem $14: 2161-2175$

Nutt MO, Hughes JB, Wong MS (2005) Designing Pd-on-Au bimetallic nanoparticle catalysts for trichloroethene hydrodechlorination. Environ Sci Technol 39:1346-1353

Pal T, Sau TK, Jana NR (1997) Reversible formation and dissolution of silver nanoparticles in aqueous surfactant media. Langmuir 13:1481-1485

Park J-I, Cheon J (2001) Synthesis of "Solid Solution" and "CoreShell" type cobalt-platinum magnetic nanoparticles via transmetalation reactions. J Am Chem Soc 123:5743-5746

Ponder S, Darab JG, Bucher J, Caulder D, Craig I, Davis L, Edelstein N, Lukens W, Nitsche H, Rao L, Shuh DK, Mallouk TE (2001) Surface chemistry and electrochemistry of supported zerovalent iron nanoparticles in the remediation of aqueous metal contaminants. Chem Mater 13:479-486

Pouretedal HR, Keshavarz MH (2010) Synthesis and characterization of $\mathrm{Zn} 1-\mathrm{XCuXS}$ and $\mathrm{Zn} 1-\mathrm{XNiXS}$ nanoparticles and their applications as photocatalyst in Congo red degradation. J Alloys Compounds 501:130-135

Pradhan N, Pal A, Pal T (2001) Catalytic reduction of aromatic nitro compounds by coinage metal nanoparticles. Langmuir 17:1800-1802

Sau TK, Murphy CJ (2004) Room temperature, high-yield synthesis of multiple shapes of gold nanoparticles in aqueous solution. $\mathbf{J}$ Am Chem Soc 126:8648-8649

Scholten PC, Felius JAP (1990) The magnetical and rheological behavior of aggregating magnetic suspensions. J Magn Magn Mate 85:107-113

Sharma P, Kumar R, Chauhan S, Singh D, Chauhan MS (2014) Facile growth and characterization of $\alpha-\mathrm{Fe}_{2} \mathrm{O}_{3}$ nanoparticles for photocatalytic degradation of methyl orange. J Nanosci Nanotechnol 14:6153-6157

Shin KS, Choi J-Y, Park CS, Jang HJ, Kim K (2009) Facile synthesis and catalytic application of silver-deposited magnetic nanoparticles. Catal Lett 133:1-7

Sihai C, David LC (2004) Silver nanoplates: size control in two dimensions and formation mechanisms. J Phys Chem B 108:5500-5506

Siwach OP, Sen P (2008) Fluorescence properties of Fe nanoparticles prepared by electro-explosion of wires. Mater Sci Eng B 149:99-104

Snoussi Y, Bastide S, Abderrabba M, Chehimi MM (2018) Sonochemical synthesis of $\mathrm{Fe}_{3} \mathrm{O}_{4} @ \mathrm{NH}_{2}$-mesoporous silica@ Polypyrrole/
Pd: a core/double shell nanocomposite for catalytic applications. Ultras Sonochem 41:551-561

Stoeva SI, Huo F, Lee J-S, Mirkin CA (2005) Three-layer composite magnetic nanoparticle probes for DNA. J Am Chem Soc 127:15362-15363

Sun S, Murray CB, Weller D, Folks L, Moser A (2000) Monodisperse FePt nanoparticles and ferromagnetic FePt nanocrystal superlattices. Science 287:1989-1992

Sureshkumar M, Siswanto DY, Lee C-K (2010) Magnetic antimicrobial nanocomposite based on bacterial cellulose and silver nanoparticles. J Mater Chem 20:6948-6955

Talebi R, Nasiri M, Rahnamaeiyan S (2016) Synthesis, characterization and optical properties of lanthanum doped zinc ferrite nanoparticles prepared by sol-gel method. J Mater Sci Mater Electron 27:1500-1506

Tsang SC, Yu CH, Gao X, Tam K (2006) Silica-encapsulated nanomagnetic particle as a new recoverable biocatalyst carrier. J Phys Chem B 110:16914-16922

Umamaheswari C, Lakshmanan A, Nagarajan NS (2018) Green synthesis, characterization and catalytic degradation studies of gold nanoparticles against congo red and methyl orange. J Photochem Photobiol B 178:33-39

Umpierre AP, de Jesus E, Dupont J (2011) Turnover numbers and soluble metal nanoparticles. Chem Cat Chem 3:1413-1418

Vidhu VK, Philip D (2014) Catalytic degradation of organic dyes using biosynthesized silver nanoparticles. Micron 56:54-62

Wang C, Zhang W (1997) Synthesizing nanoscale iron particles for rapid and complete dechlorination of TCE and PCBs. Environ Sci Technol 31:2154-2156

Wang Y, Li H, Zhang J, Yan X, Chen Z (2016) $\mathrm{Fe}_{3} \mathrm{O}_{4}$ and Au nanoparticles dispersed on the graphene support as a highly active catalyst toward the reduction of 4-nitrophenol. Phys Chem Chem Phys 18:615-623

Wang J, Liu G, Liu Y, Zhou C, Wu Y (2017) Photocatalytic degradation of methyl orange by $\mathrm{Fe}_{2} \mathrm{O}_{3}-\mathrm{Fe}_{3} \mathrm{O}_{4}$ nanoparticles and $\mathrm{Fe}_{2} \mathrm{O}_{3}-$ $\mathrm{Fe}_{3} \mathrm{O}_{4}$-montmorillonite nanocomposites. Clean-Soil Air, Water 45:1600472

Wei Z, Zhou Z, Yang M, Lin C, Zhao Z, Huang D, Chen Z, Gao J (2011) Multifunctional Ag@ $\mathrm{Fe}_{2} \mathrm{O}_{3}$ yolk-shell nanoparticles for simultaneous capture, kill, and removal of pathogen. J Mater Chem 21:16344-16348

Wiley B, Sun Y, Mayers B, Xia Y (2005) Shape-controlled synthesis of metal nanostructures: the case of silver. Chem Eur J 11:454-463

Wu W, Wu Z, Yu T, Jiang C, Kim W-S (2015) Recent progress on magnetic iron oxide nanoparticles: synthesis, surface functional strategies and biomedical applications. Sci Technol Adv Mater 16:023501

Xiong J, Wang Y, Xue Q, Wu X (2011) Synthesis of highly stable dispersions of nanosized copper particles using L-ascorbic acid. Green Chem 13:900-904

Xu Y, Zhang W-XS (2000) Subcolloidal Fe/Ag particles for reductive dehalogenation of chlorinated benzenes. Ind Eng Chem Res 39:2238-2244

Yu D, Yam VW-W (2005) Hydrothermal-induced assembly of colloidal silver spheres into various nanoparticles on the basis of HTABmodified silver mirror reaction. J Phys Chem B 109:5497-5503

Zhang W-X (2003) Nanoscale iron particles for environmental remediation: an overview. J Nanoparticle Res 5:323-332

Zhang W, Wang C, Lien H (1998) Treatment of chlorinated organic contaminants with nanoscale bimetallic particles. Catal Today 40:387-395

Zhang J, Roll D, Geddes CD, Lakowicz JR (2004) Aggregation of silver nanoparticle-dextran adducts with concanavalin A and competitive complexation with glucose. J Phys Chem B 108:12210-12214

Zhang H, Jin M, Liu H, Wang J, Kim MJ, Yang D, Xie Z, Liu J, Xia Y (2011) Synthesis of Pd-Pt bimetallic nanocrystals with a concave 
structure through a bromide-induced galvanic replacement reaction. ACS Nano 5:6078-6089

Zhang Y, Gao F, Wanjala B, Li Z, Cernigliaro G, Gu Z (2016) High efficiency reductive degradation of a wide range of azo dyes by $\mathrm{SiO}_{2}$-Co core-shell nanoparticles. Appl Catal B 199:504-513
Publisher's Note Springer Nature remains neutral with regard to jurisdictional claims in published maps and institutional affiliations 